\title{
Nitromethane Ignition Behind Reflected Shock Waves: Experimental and Numerical Study
}

\author{
O. Mathieu'*, B. Giri², A. R. Agard², T. N. Adams², J. D. Mertens², and E. L. Petersen ${ }^{1}$ \\ ${ }^{1}$ Texas A\&M University, Department of Mechanical Engineering, College Station, Texas, USA \\ ${ }^{2}$ Trinity College, Department of Engineering, Hartford, Connecticut, USA
}

\begin{abstract}
Ignition delay times for nitromethane have been measured behind reflected shock waves over wide ranges of temperature (875-1595 K); pressure (2.0-35 atm); equivalence ratio (0.5, 1.0, and 2.0); and dilution (99, 98, 95, and 90\% Ar by volume) using a L9 Taguchi array. Emission from excited-state hydroxyl radials $\left(\mathrm{OH}^{*}\right)$ was the primary diagnostic for determining the ignition delay times from the experiments. Results showed that nitromethane's ignition delay time is very sensitive to most of the experimental parameters that were varied. In addition, the $\mathrm{OH}^{*}$ profile for nitromethane presents an interesting double feature, with the relative intensity between the two peaks varying greatly depending on the experimental conditions. A detailed chemical kinetics mechanism was assembled from previous work by the authors and from sub-mechanisms from the literature. The latest theoretical work on nitromethane decomposition was used, and the final mechanism satisfactorily reproduces the ignition delay time data from the present study, as well as nitromethane and $\mathrm{CH}_{4} / \mathrm{NOx}$ ignition delay time data available from the literature.
\end{abstract}

Keywords: Nitromethane, Ignition Delay Time, L9 Taguchi Array, Detailed Kinetics Modeling, Shock Tube.

1 Introduction

Due to its various properties as a fuel component, there is significant interest in the detailed understanding of nitromethane's combustion chemistry. When blended with gasoline, nitromethane (NM) leads to an increase in octane sensitivity (sensitivity = RON-MON) [1], which can be beneficial for preventing knock in modern, direct-injected, boosted gasoline engines [2]. NM also has a high lubricity, which makes it an interesting fuel component for model and racecar engines [3]. Additionally, the relatively small size of the NM molecule with regards to its oxygen content $\left(\mathrm{CH}_{3} \mathrm{NO}_{2}\right)$ allows for the introduction of more fuel into the cylinder for a given quantity of air, which, despite the lower energy density of NM compared to a regular gasoline fuel, leads to a higher energy output, useful for racecar engines. Finally, NM is often used as a reference component to understand the combustion mechanism of propellants [4,5] and is itself a candidate liquid monopropellant [6]. Despite these various areas of interest, as described in more detail below, the combustion chemistry of nitromethane has been investigated in only a limited number of studies [3] (detonations studies are, in contrast, more common [7-101112]).

A detailed kinetics mechanism was proposed in the study of Glarborg et al. [13] in 1999, and this model was able to predict with fair accuracy the available literature shock-tube data on nitromethane decomposition. In their study, the pre-1999 experimental work was used to re-evaluate the reaction rates of the following important reactions:

(C) 2016. This manuscript version is made available under the Elsevier user license http://www.elsevier.com/open-access/userlicense/1.0/ 


$$
\begin{gathered}
\mathrm{CH}_{3} \mathrm{NO}_{2}(+\mathrm{M}) \stackrel{\leftrightarrows}{\leftrightarrows} \mathrm{CH}_{3}+\mathrm{NO}_{2}(+\mathrm{M}) \\
\mathrm{CH}_{3}+\mathrm{NO}_{2} \leftrightarrows \mathrm{CH}_{3} \mathrm{O}+\mathrm{NO}
\end{gathered}
$$

According to Glarborg et al., the reactions $\mathrm{CH}_{3} \mathrm{NO}_{2} \leftrightarrows \mathrm{CH}_{3} \mathrm{ONO}$ and $\mathrm{CH}_{3}+\mathrm{NO}_{2}(+\mathrm{M}) \leftrightarrows \mathrm{CH}_{3} \mathrm{ONO}$ $(+\mathrm{M})$ can be considered negligible under practical combustion conditions. In addition, the formation of $\mathrm{NO}$ directly from $\mathrm{CH}_{3} \mathrm{NO}_{2}$ decomposition was not considered.

Over the past few years, detailed kinetics mechanisms on NM combustion have seen constant improvement in the literature. These contemporary kinetics mechanisms for NM [3,4,14,15] all rely on the rate for R1 estimated by Glarborg and coworkers [13]. In the study from Boyer and Kuo [4] for example, the flame structure of NM at high pressure was investigated numerically using a detailed kinetics model they developed. Flame species formed in a premixed flame of NM in Ar were identified by Tian et al. [14], and a detailed kinetics mechanism was validated with these data. However, as pointed out by Brequigny et al. [3], these two mechanisms are limited as they are either designed for high pressure only (20-150 atm) [4] or have only been validated with a single equivalence ratio [14]. A more-comprehensive mechanism based on the one from Glarborg et al. [13] was then developed by Zhang et al. [15], who validated a chemical scheme against species and temperature profiles from laminar flames at different equivalence ratios (1.0, 1.45, and 2.0). This mechanism was recently improved by Brequigny et al. [3] who also measured the laminar flame speed of NM between 0.5 and 3 bar. The maximum flame speed was observed for lean mixtures in the study of Brequigny et al., around $\phi=0.7-0.8$, and their model was able to predict this result. However, Nauclér et al. [16] analyzed the results of Brequigny et al. and showed that this result was due to the equation Brequigny et al. used for determining the equivalence ratio $\left(\mathrm{CH}_{3} \mathrm{NO}_{2}+0.75\left(\mathrm{O}_{2}+3.76 \mathrm{~N}_{2}\right) \leftrightarrows \mathrm{CO}_{2}+1.5 \mathrm{H}_{2} \mathrm{O}+3.32 \mathrm{~N}_{2}\right)$. Nauclér et al. used a different set of ideal products to determine the equivalence ratio $\left(\mathrm{CH}_{3} \mathrm{NO}_{2}+1.25 \mathrm{O}_{2} \leftrightarrows\right.$ $\mathrm{CO}_{2}+1.5 \mathrm{H}_{2} \mathrm{O}+\mathrm{NO}$ ) and found that the maximum flame speed was then obtained on the fuel-rich side (at an equivalence ratio of around 1.2), in agreement with results generally observed with other hydrocarbons $[17,18]$.

To further refine and validate NM detailed kinetics mechanisms over wide ranges of conditions, more experimental data was necessary. Ignition delay time measurements in shock tubes, thanks to their accuracy and the simplicity of their modeling, are extremely valuable to rapidly assess the global accuracy of a mechanism and to help improve predictions. Unfortunately, to date there are no ignition delay time data available in the literature (except for the ignition delay time measurements by Kang et al. [19], for which the pressure condition was not reported, making these data rather difficult to use to validate a kinetics model).

In addition to this lack of data, previous mechanisms for NM do not include the latest developments for NM chemistry, based on recent theoretical and experimental studies (20-22). As summarized by Annesley et al. [22], results from shock tubes and infrared multi-photon dissociation experiments historically disagree with each other in that only $\mathrm{CH}_{3}$ and $\mathrm{NO}_{2}$ have been detected in shock-tube NM decomposition, whereas the formation of NO, accounting for up to $40 \%$ of the NM consumption [23], was also observed with infrared multi-photon dissociation techniques. Theoretical studies identified a roaming isomerization of NM $\left(\mathrm{CH}_{3} \mathrm{NO}_{2} \rightarrow\left[\mathrm{CH}_{3} \mathrm{ONO}{ }^{*}\right] \rightarrow \mathrm{CH}_{3} \mathrm{O}+\mathrm{NO}\right)$ competing with the simple bond fission pathway $\left(\mathrm{CH}_{3} \mathrm{NO}_{2} \leftrightarrows\right.$ $\mathrm{CH}_{3}+\mathrm{NO}_{2}$ ). The branching ratio between these two pathways was predicted to be strongly pressure dependent between 1 and 200 Torr above $1000 \mathrm{~K}$, transitioning from roaming dominated to bond fission dominated [20]. Annesley et al. [22] investigated both theoretically and experimentally (in a shock tube at pressures between 30 and 120 Torr) the competition between roaming mediated isomerization and thermal dissociation of NM. Their result was consistent with the previous theoretical work, although the pressure dependence of the branching ratio is not as strong as predicted by Zhu et al. [20]. 
To help improve understanding of NM combustion, the scope of the present study was twofold. First, new experimental measurements were performed under conditions never before investigated. Ignition delay times $\left(\tau_{\text {ign }}\right)$ were measured over large ranges of temperature, pressure, dilution, and equivalence ratio in a shock tube. A test matrix was developed to limit the number of experiments while still validating the model over a wide range of conditions. The second main aspect of this study was to propose a detailed kinetics mechanism capable of reproducing the results from the present study along with other nitromethane data and hydrocarbon/NOx ignition delay time data from the literature. The first part of the paper details the experimental setups used during this study. The experimental results obtained with these setups are then presented and compared with detailed kinetics models from the literature and with a detailed mechanism proposed in this study. Finally, the experimental results are explained by numerical analysis using the mechanism.

2 Experimental Setup

2.1. Description of the apparatus

Ignition delay times $\left(\tau_{\text {ign }}\right)$ were measured in a high-pressure shock tube. The driver section is $2.46 \mathrm{~m}$ long (76.2-mm i.d.), and the driven section is $4.72 \mathrm{~m}$ long (152.4- $\mathrm{mm}$ i.d.). Test pressure in the shock tube was monitored by one PCB 134A transducer located at the end wall and one Kistler 603 B1 transducer located at the sidewall. More details and schematics of the shock-tube setup can be found in Aul et al. [24].

The measurement section is equipped with 5 pressure transducers (PCB P113A) equally spaced by 406 $\mathrm{mm}$ and mounted flush with the inner surface. The last transducer is located $16 \mathrm{~mm}$ before the shock-tube endwall. These transducers delivered a signal upon the passage of the incident shock wave, and its velocity was determined using four Fluke PM-6666 timer/counter boxes. A curve fit of these four velocities was then extrapolated to determine the incident wave speed at the endwall location. Post reflected-shock conditions were obtained using this extrapolated wave speed in conjunction with one-dimensional shock relations and the initial conditions at the test region. This method was proven to maintain the uncertainty in the temperature determination behind reflected shock waves $\left(T_{5}\right)$ below $10 \mathrm{~K}$ as shown in Petersen et al. [25].

\subsection{Optical diagnostic}

Ignition delay times were determined using the chemiluminescence emission from the $\mathrm{A}^{2} \Sigma^{+} \rightarrow \mathrm{X}^{2} \Pi$ transition of the excited-state hydroxyl radical $\left(\mathrm{OH}^{*}\right)$ at $307 \pm 10 \mathrm{~nm}$. During this study, an unusually low level of $\mathrm{OH}^{*}$ chemiluminescence was observed, leading to a relatively low signal-to-noise ratio (SNR) compared to former studies from our group [26,27]. To illustrate this low level of $\mathrm{OH}^{*}$ chemiluminescence, the most recent NM mechanism from Brequigny et al. [3] was coupled with the $\mathrm{OH}^{*}$ sub-mechanism used in Mathieu et al. [26] (comprised of the $\mathrm{OH}^{*}$ mechanism from Hall and Petersen [28], along with the reaction $\mathrm{N}_{2} \mathrm{O}+\mathrm{H} \leftrightarrows \mathrm{N}_{2}+\mathrm{OH}^{*}$ from Hidaka et al. [29]). Numerical $\mathrm{OH}^{*}$ profiles are then compared between NM and $\mathrm{CH}_{4}$ for similar equivalence ratios, temperatures, ignition delay times, and pressures. Results are visible in Fig. 1 for (a) mixtures of $\mathrm{CH}_{4}$ and $\mathrm{CH}_{3} \mathrm{NO}_{2}$ at $1500 \mathrm{~K}$ (10 atm, $\phi=1,98 \% \mathrm{Ar}$ ); and (b) for the same mixtures and the same conditions except that the $\mathrm{CH}_{4}$ mixture is now at $1745 \mathrm{~K}$. As can be seen in Fig. 1(a), the computed $\mathrm{OH}^{*}$ profile from nitromethane combustion presents a double peak; the first peak is always found around time zero and is, by far, the largest intensity (as per the model). The second peak at around $200 \mu \mathrm{s}$ in Fig. 1 corresponds to the maximum $\mathrm{OH}^{*}$ intensity for the main ignition event, is a much smaller intensity, and can barely be seen on the scale. However, only one peak is resolved at around $3250 \mu$ s for the ignition of $\mathrm{CH}_{4}$. This time difference for the ignition peaks illustrates the large difference in reactivity between methane and nitromethane. As shown later in the paper, these two peaks for NM were also observed experimentally, and the origins and respective amplitudes of these peaks are discussed. Since ignition delay time 
measurements in shock tubes are limited by a maximum observation test time (around 100 to $1500 \mu$ s in this study), the respective amount of $\mathrm{OH}^{*}$ produced by $\mathrm{CH}_{4}$ and $\mathrm{NM}$ (the second peak for the latter) are also compared at conditions for which the maximum $\mathrm{OH}^{*}$ occurs at the same time. Fig. 1 shows that at $10 \mathrm{~atm}$, $98 \% \mathrm{Ar}$, and $\phi=1.0$, this is achieved by increasing the $\mathrm{CH}_{4}$ temperature to $1745 \mathrm{~K}$, at which $\mathrm{CH}_{4}$ produces around 300 times more $\mathrm{OH}^{*}$ than NM. Changing only dilution level to $90 \%$ Ar results in $\mathrm{CH}_{4}$ producing around 30 times more $\mathrm{OH}^{*}$ than $\mathrm{NM}$ (not shown on Fig. 1). This very low level of $\mathrm{NM} \mathrm{OH}^{*}$ emission is the reason for the low SNR of experimental $\mathrm{OH}^{*}$ profiles in this study. Despite the lower-than-normal SNR, the key features were nonetheless adequately resolved for determining ignition delay times.
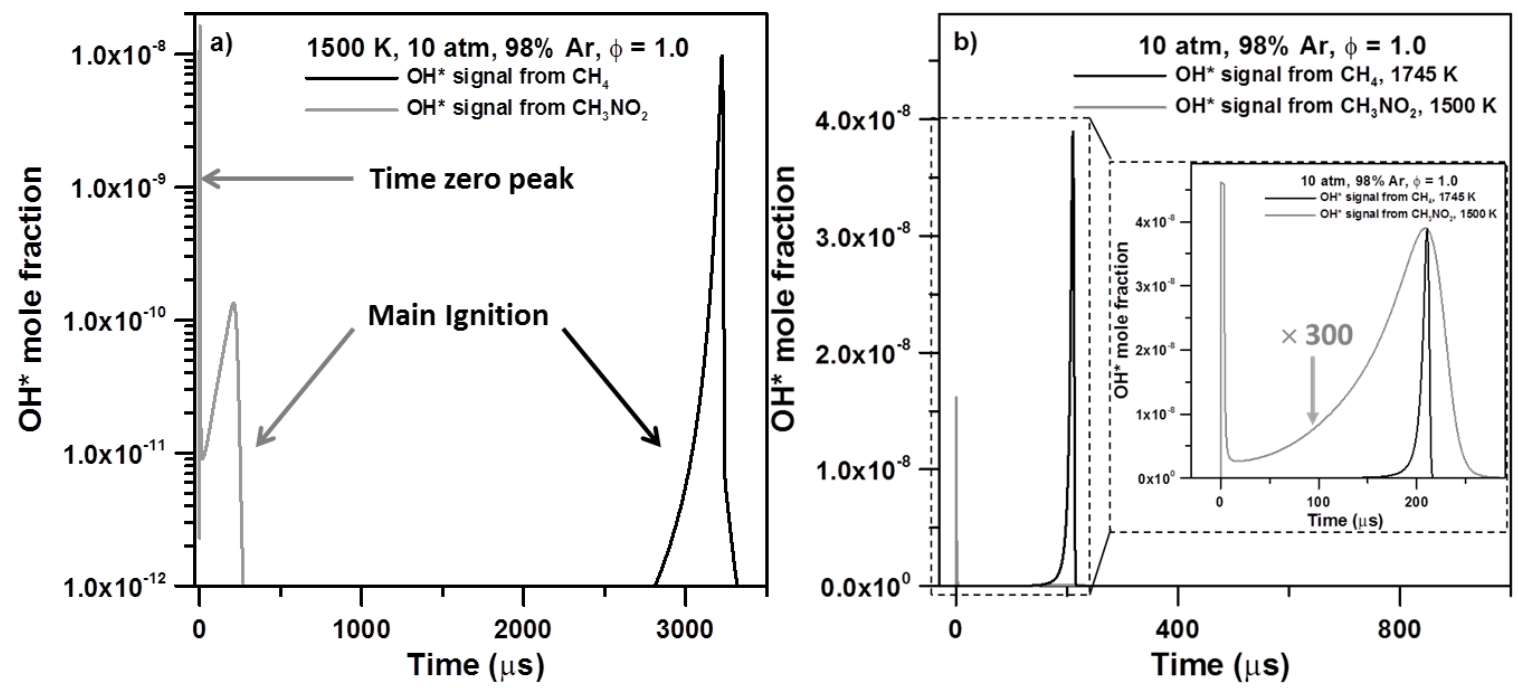

Figure 1: Computed $\mathrm{OH}^{*}$ profiles using the mechanism of Brequigny et al. [3] at $10 \mathrm{~atm}$, for mixtures of methane and nitromethane diluted in $98 \% \mathrm{Ar}$ at a) the same temperature $(1500 \mathrm{~K})$, and b) the same ignition delay time $\left(1500 \mathrm{~K}(\mathrm{NM})\right.$ and $\left.1745 \mathrm{~K}\left(\mathrm{CH}_{4}\right)\right)$. The zoomed-in section presents the same results but with the $\mathrm{OH}^{*}$ profiles for NM multiplied by around 300 to clearly visualize the time at which the $\mathrm{OH}^{*}$ ignition peak is reached for the two mixtures.

\subsection{Mixture preparation}

Mixtures were prepared manometrically in a stainless-steel mixing tank (3.05-m length, 15.24-cm i.d.) equipped with a perforated stinger traversing its center to allow for rapid, turbulent mixing. Nitromethane $(>98.5 \%$, Sigma Aldrich), liquid at room temperature, was introduced into a vial and de-gassed several times prior to being evaporated to no more than $60 \%$ of its vapor pressure at room temperature. The gases $\left(\mathrm{O}_{2}\right.$ (Praxair) and Ar (Acetylene Oxygen Company)) were ultra-high purity grade (99.999\%). Mixtures were allowed to rest for at least 2 hours prior to making the first run to further ensure homogeneity through diffusion processes.

A test matrix was developed to minimize the number of experiments yet still validate the model over a wide range of conditions in terms of fuel concentrations, pressures, and equivalence ratios. Three levels of each of the aforementioned variables were assembled into a L9 Taguchi array [30], a method that has been used several times by our group in the past for the efficient, balanced coverage of a wide parameter space [2432]. Table 1 summarizes the mixtures covered within this $L 9$ array.

Table 1: Mixtures and experimental conditions covered by the L9 array (*: Maximum feasible pressure due to nitromethane vapor pressure limitation). 


\begin{tabular}{|c|c|c|c|}
\hline Mixture\# & $\mathbf{P}(\mathbf{a t m})$ & $\boldsymbol{\phi}$ & $\mathbf{0 ~ A r}$ \\
\hline $\mathbf{1}$ & 2 & 0.5 & 90 \\
\hline $\mathbf{2}$ & 2 & 1.0 & 95 \\
\hline $\mathbf{3}$ & 2 & 2.0 & 98 \\
\hline $\mathbf{4}$ & 10 & 0.5 & 95 \\
\hline $\mathbf{5}$ & 10 & 1.0 & 98 \\
\hline $\mathbf{6}$ & 10 & 2.0 & 90 \\
\hline $\mathbf{7}$ & 30 & 0.5 & 98 \\
\hline $\mathbf{8}$ & $10^{*}$ & 1.0 & 90 \\
\hline $\mathbf{9}$ & $14^{*}$ & 2.0 & 95 \\
\hline
\end{tabular}

As indicated in Table 1 for mixtures 8 and 9, due to the relatively low vapor pressure of nitromethane, it was anticipated that for low- and intermediate-dilution levels it would not always be possible to reach a reflected-shock pressure of $30 \mathrm{~atm}$ for some mixtures. This limitation is due to the inability of reaching high enough pressures of NM vapor in the mixing tank to allow total mixing tank pressures high enough to fill the shock tube to desired levels. To overcome this limitation, mixtures 8 and 9 were prepared directly in the driven section of the shock tube. Due to the absence of a perforated stinger or any other mixing device, it was found necessary to leave the mixture at rest for at least 10 hours prior to running the experiment (to ensure homogeneity by diffusion process). The measured leak rate of the shock tube was below 1 mTorr/min, which induced an uncertainty in the equivalence ratio of the mixture that is well within the uncertainty in the ignition delay time measurement and temperature determination, and was therefore considered negligible (the uncertainty in the ignition delay time is discussed below). To illustrate this statement, Mix 9 would at worst case be between $\phi=1.97$ and 1.98 instead of the projected $\phi=2.0$, for example.

Polycarbonate (lexan) and pre-scored aluminum diaphragms were used. A cross-shaped cutter was employed with polycarbonate diaphragms to facilitate breakage of the diaphragm and prevent diaphragm fragments from tearing off. Helium was used primarily as the driver gas during this study, although air or nitrogen was sometimes added to the helium driver gas for high-pressure experiments, to reduce the speed of the incident shock wave and reach lower temperatures without having to increase the initial pressure in the test section (because of the limitation induced by the low vapor pressure of NM). As can be seen in Table 2, additional mixtures and conditions to the L9 array were also studied. Mixtures 4, 5, and 7 were also investigated at low pressure ( $\sim 2 \mathrm{~atm})$, while a higher dilution level of Ar was investigated and designated as Mix 10. 
Table 2: Mixture compositions and conditions investigated for the ignition delay time measurements.

\begin{tabular}{|c|c|c|c|c|c|c|}
\hline Mixture & $\phi$ & $\mathrm{CH}_{3} \mathrm{NO}_{2} \%$ & $\mathrm{O}_{2} \%$ & $\mathrm{Ar} \%$ & $\begin{array}{c}\text { Avg. P }{ }_{5} \\
\text { (atm) }\end{array}$ & $\mathrm{T}_{5}$ range $(\mathrm{K})$ \\
\hline 1 & 0.5 & 4.0 & 6.0 & 90.0 & 2.1 & $920-1215$ \\
\hline 2 & 1.0 & 2.857 & 2.143 & 95.0 & 1.9 & $1215-1495$ \\
\hline 3 & 2.0 & 1.455 & 0.545 & 98.0 & 1.8 & $1420-1595$ \\
\hline \multirow{2}{*}{4} & \multirow{2}{*}{0.5} & \multirow{2}{*}{2.0} & \multirow{2}{*}{3.0} & \multirow{2}{*}{95.0} & 2.0 & $1080-1450$ \\
\hline & & & & & 11.5 & $955-1210$ \\
\hline \multirow{2}{*}{5} & \multirow{2}{*}{1.0} & \multirow{2}{*}{1.143} & \multirow{2}{*}{0.857} & \multirow{2}{*}{98.0} & 1.9 & $1300-1575$ \\
\hline & & & & & 10.4 & $1255-1485$ \\
\hline 6 & 2.0 & 7.273 & 2.727 & 90.0 & 8.6 & $890-1010$ \\
\hline \multirow{2}{*}{7} & \multirow{2}{*}{0.5} & \multirow{2}{*}{0.8} & \multirow{2}{*}{1.2} & \multirow{2}{*}{98.0} & 2.0 & $1215-1460$ \\
\hline & & & & & 34.3 & $1185-1375$ \\
\hline 8 & 1.0 & 5.714 & 4.286 & 90.0 & 9.4 & $895-1055$ \\
\hline 9 & 2.0 & 3.64 & 1.36 & 95.0 & 13.7 & $875-1080$ \\
\hline 10 & 1.0 & 0.571 & 0.429 & 99.0 & 1.9 & $1340-1540$ \\
\hline
\end{tabular}

3 Experimental Results

3.1 Methods of determination of the ignition delay time

Two definitions of the ignition delay time are used in this study. The first definition corresponds to the time between the passage of the reflected shock wave, indicated by a pressure jump in the signal delivered by the sidewall pressure transducer (defining time 0 in our study), and the intersection of lines drawn along the steepest rate-of-change of $\mathrm{OH}^{*}$ de-excitation and a horizontal line which defines the zero-concentration level, as can be seen in Fig. 2 (a) and (b). The moment of ignition was also defined as the top of the ignition peak $\left(\tau_{\text {ign } 100 \%}\right)$. Note that due to a continuous increase in the slope of the main ignition peak right after the first $\mathrm{OH}^{*}$ peak, the ignition delay time was measured at the peak of the $\mathrm{OH}^{*}$ signal only for Mix 7 high-pressure ( $\sim 35 \mathrm{~atm})$ cases (Fig. 3).

As can be seen in Figs. 2 and 3, the $\mathrm{OH}^{*}$ profiles of $\mathrm{NM}$ vary significantly with the equivalence ratio, the pressure, and the dilution level. Several $\mathrm{OH}^{*}$ profiles illustrating these variations are presented and discussed later in this paper. The first peak right after the arrival of the reflected shock wave, observed here with NM, was also observed and discussed with n-nonane in Rotavera et al. [33]. The appearance of this peak was explained by the formation of a methyl radical followed by a series of $\mathrm{H}$-abstractions leading to $\mathrm{CH}$; the latter reacting with $\mathrm{O}_{2}$ to form $\mathrm{OH}^{*}$ as described in Hall and Petersen [28]. Due to the propensity of NM to form $\mathrm{CH}_{3}$ by thermal dissociation at the high temperatures investigated, this mechanism is believed to be responsible for the first $\mathrm{OH}^{*}$ peak observed here.

It is worth mentioning that the width and intensity of this first peak is also subject to experiment-induced broadening. This broadening is due to the passage of the reflected shock wave across the path of the optical setup, as detailed in Rotavera et al. [33]. The importance of this broadening effect varies with the velocity of the reflected shock wave (which varied over a large span during this study due to the large range of conditions investigated). If the response function of the experimental setup were known, it can be used to "correct" the computed result from the model to better compare with the actual experiment. However, characterizing the broadening of the first peak was beyond the scope of this work, so no attempt was made to further analyze the magnitude and shape of the first peak. To document the data behavior and to serve as a qualitative 
indication of the evolution of this first peak as a function of the mixture and condition, the evolution with the temperature of the ratio between the maximum intensity of the first peak and the maximum intensity of the second (ignition) peak is provided as supplementary material for each mixture and condition. Note that Mix 6, Mix 8, and Mix 9 do not exhibit any discernable first peak.
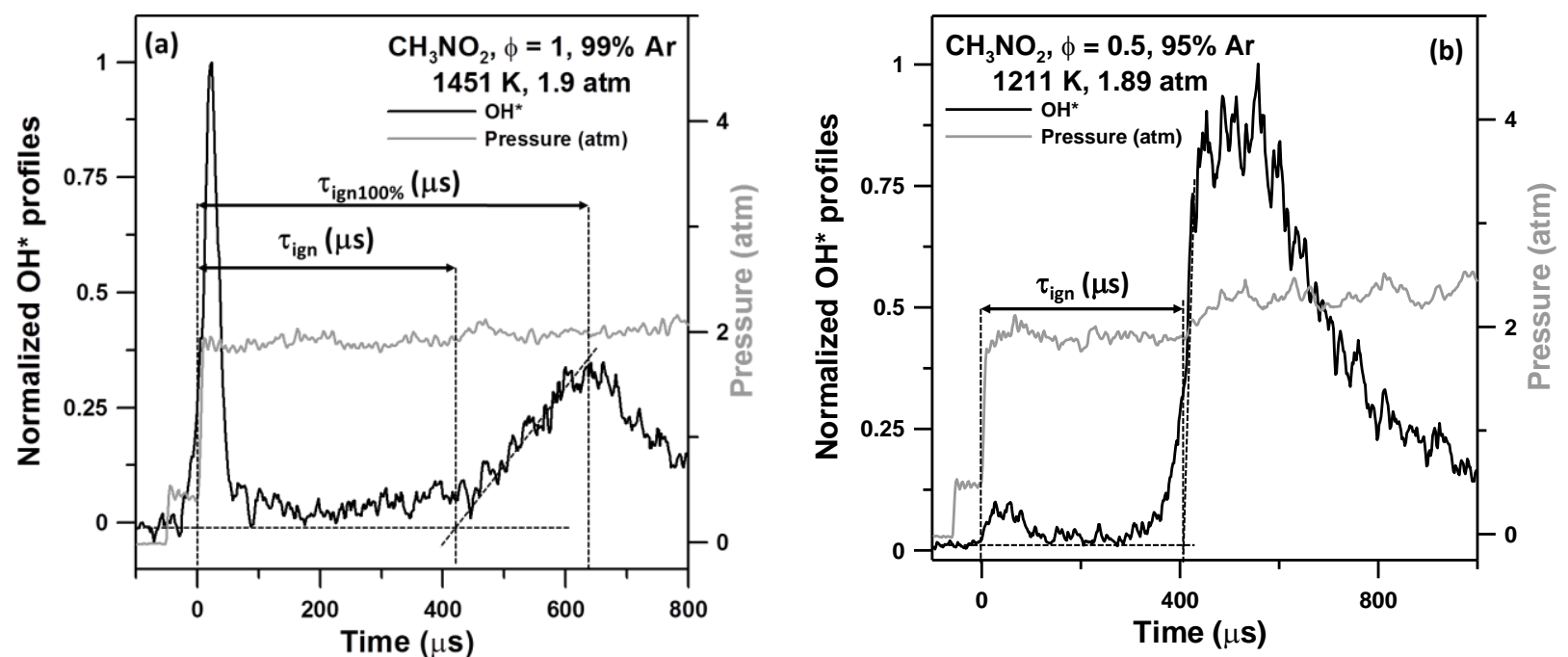

Figure 2: Typical sidewall experimental pressure and $\mathrm{OH}^{*}$ profiles and methods of determination of the ignition delay time.

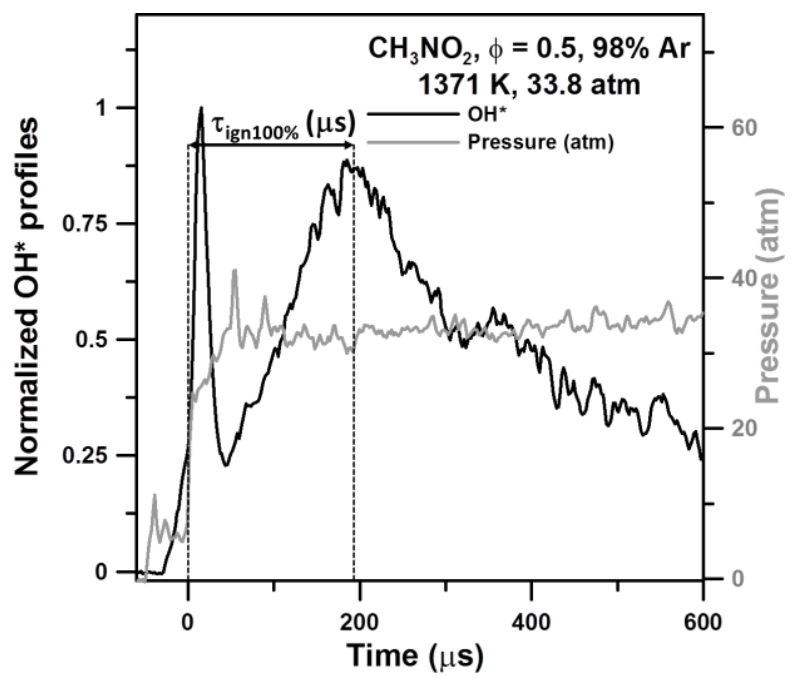

Figure 3: Typical sidewall experimental pressure and $\mathrm{OH}^{*}$ profiles and method of determination of the ignition delay time for the high-pressure $(\sim 35 \mathrm{~atm})$ cases with Mix 7.

There are essentially two main sources of uncertainty in the ignition delay time: the uncertainty in the determination of the temperature behind the reflected shock wave $\left(\mathrm{T}_{5}\right)$ and the uncertainty associated with the determination of the steepest rate of change or maximum of $\mathrm{OH}^{*}$ profiles. Under the present conditions, the experimental setup and method used allow for a determination of $\mathrm{T}_{5}$ within less than $10 \mathrm{~K}$, which is a typical largest uncertainty with classic hydrocarbons [25-27, 24]. However, due to the low intensity of the $\mathrm{OH}^{*}$ profile and associated SNR of some experiments, the total uncertainty in $\tau_{\text {ign }}$ reported in this study is estimated to be up to $20 \%$ (compared to $10 \%$ or less in our previous studies). This includes the minimal 
temperature variation with facility $\mathrm{dP} / \mathrm{dt}$, which was always observed to be less than $2 \% / \mathrm{ms}$ before the ignition event. All of the ignition delay times presented in the figures below are reported with their respective associated conditions $\left(T_{5}, P_{5}\right)$ in the Supplementary Material section.

\subsection{Experimental results}

Although useful for covering a wide range of conditions in an efficient manner, a minor drawback of a L9 array is that it does not allow direct comparison of the data by varying only one parameter at a time. However, since a few extra conditions and mixtures were studied, it was possible to compare the effects of changing only equivalence ratio, pressure, or dilution level at a number of conditions, and these are shown in the following figures. $\mathrm{OH}^{*}$ chemiluminescence profiles are also presented in this section to exhibit the effects of changes in some conditions on the shape of the profiles.

\section{Equivalence ratio effect:}

The effect of the equivalence ratio on the ignition delay time of NM is visible in Fig. 4. In this figure, results between $\phi=0.5$ and 2.0, for mixtures diluted in 98\% Ar and at $1.9 \mathrm{~atm}$, are presented for the two kinds of methods used for the ignition delay time measurements. As can be seen, increasing the equivalence ratio leads to a significant increase in the ignition delay time under these conditions. For example, Fig. 4 (a), at a temperature around $1420 \mathrm{~K}$, the ignition delay time is increased by more than a factor 3 when the equivalence ratio is doubled, from $0.5(135 \mu \mathrm{s})$ to $1.0(450 \mu \mathrm{s})$. This increase becomes larger than a factor of 13 when comparing the fuel lean $(135 \mu \mathrm{s})$ and the fuel rich $(1800 \mu \mathrm{s})$ cases at this temperature. A similar behavior is observed for the peak $\mathrm{OH}^{*}$ method of determination of the ignition delay time ( $\tau_{\text {ign } 100 \%, \text { Fig. } 4}$ (b)).

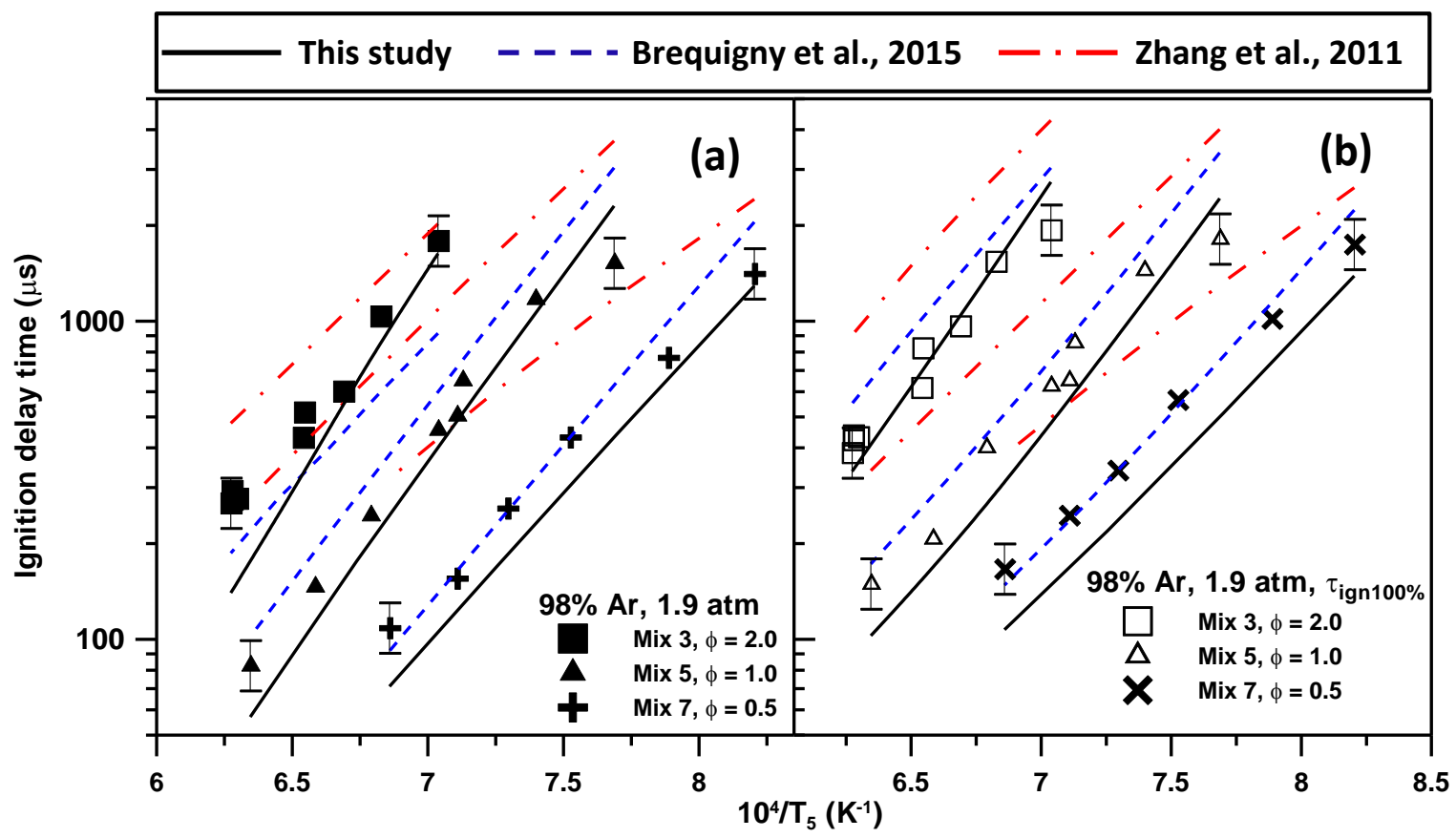

Figure 4: Effect of the equivalence ratio on the ignition delay time for $98 \% \mathrm{Ar}$ and reflected-shock pressures around $1.9 \mathrm{~atm}$. (a) using the maximum slope of $\mathrm{OH}^{*}$ signal, and (b) using the maximum $\mathrm{OH}^{*}$ signal. 
To illustrate the variations in the $\mathrm{OH}^{*}$ profiles with equivalence ratio, normalized $\mathrm{OH}^{*}$ profiles for the 98\% Ar mixtures at low pressure are compared in Fig. 5 for (a) a similar temperature $(1465 \pm 8 \mathrm{~K}$ ) and (b) a similar ignition delay time using the maximum slope method $(445 \pm 12 \mu \mathrm{s})$. Profiles were normalized to the highest value reached, whether this value is reached on the first or the second peak. This normalization procedure makes the ignition peak look very small for the $\phi=2.0$ case in Fig. 5 (b). However, the ignition delay time is still easily identified using both definitions.

Figure 5(a) shows that for a temperature of around $1460 \mathrm{~K}$ the second peak, corresponding to the ignition event, is the highest for the fuel lean case, whereas the highest $\mathrm{OH}^{*}$ amount is reached at the first peak around $t=0$ for the stoichiometric case. One can also see that as the equivalence ratio increases, the peak corresponding to the ignition event decreases in intensity and lasts longer (gets wider). Figure 5(b) shows that when matching ignition delay times for different equivalence ratios, the maximum $\mathrm{OH}^{*}$ intensity is also reached on the first peak for the stoichiometric and fuel rich conditions, whereas the maximum is reached on the ignition peak for the fuel lean case (but the intensity between the two peaks is relatively close in this case). Again, the intensity of the ignition peak tends to decrease as the equivalence ratio increases, despite the fact that, for a given ignition delay time the temperature increases with the equivalence ratio $\left(\mathrm{OH}^{*}\right.$ intensity is typically increasing with the temperature for a given mixture, as can be seen in Fig. 1 and in Kalitan et al. [34] and de Vries et al. [35]). One can therefore conclude from these observations that the intensity of the $\mathrm{OH}^{*}$ ignition peak significantly decreases with the increase in equivalence ratio.

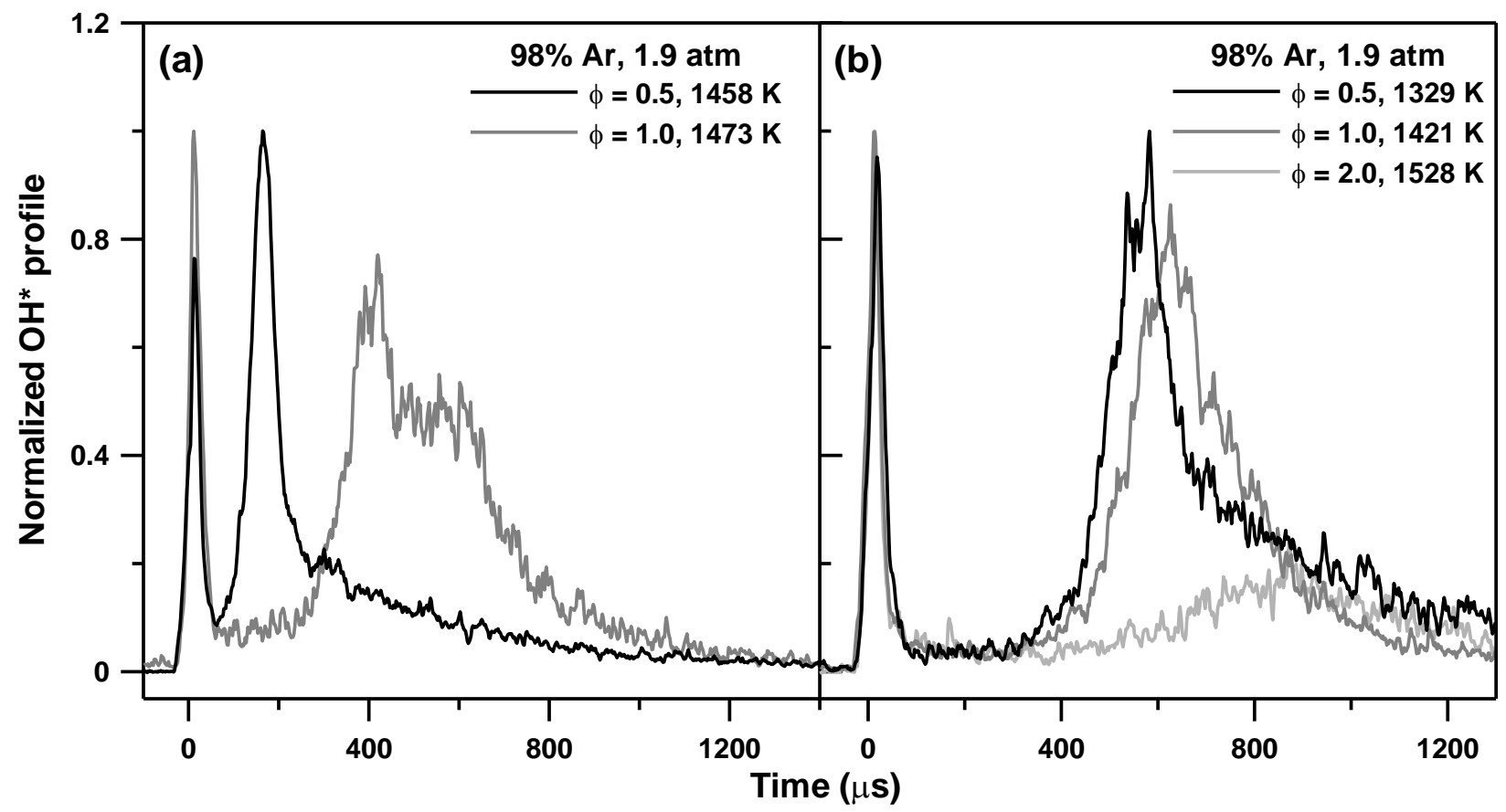

Figure 5: Evolution of the $\mathrm{OH}^{*}$ profile with time for (a) similar temperatures and (b) similar ignition delay times using the maximum slope method for mixtures diluted in $98 \% \mathrm{Ar}$, around $2 \mathrm{~atm}$, and for equivalence ratios of $0.5,1.0$, and 2.0 .

\section{Pressure effect}

The effect of pressure on the ignition delay time is visible in Fig. 6 for (a, b) Mix 4, (c, d) Mix 5, and (e, f) Mix 7. For all cases, an increase in pressure induces a decrease in the ignition delay time. However, the 
amplitude of this decrease in the ignition delay time seems to be strongly dependent on both the equivalence ratio and the dilution level. The influence of the equivalence ratio on the pressure effect can be observed by comparing results at $\tau_{\text {ign } 100 \%}$ for Mix 5 (d) and Mix 7 (f). Both mixtures were diluted in $98 \%$ Ar, but when the pressure is increased by a factor of around 5 for Mix $5(\phi=1.0)$ (from around 1.9 atm to around $10.4 \mathrm{~atm}$ ), the ignition delay time decreases by a factor between 1.5 (high temperature) and 1.7 (low temperature). For the Mix 7 case $(\phi=0.5$ ), despite a larger increase in pressure by a factor of around 17 (from about 2.0 to 34.3 atm), the ignition delay time is decreased by only a factor of around 2.0. The dilution level influence on the pressure effect can be seen by comparing data from Mix 4 (b), 95\% Ar, and Mix 7 (f), 98\% Ar, both with the same equivalence ratio (0.5). The decrease in the ignition delay time for Mix 7 (described above) is moderate despite the large increase in pressure compared to Mix 4 . The ignition delay time is decreased by a factor of around 3 when the pressure increases by a factor close to 6 with Mix 4.

The effects of pressure and temperature on the $\mathrm{OH}^{*}$ profile can be observed in Fig. 7. For a mixture at $\phi$ $=0.5$ and $95 \% \operatorname{Ar}(7 \mathrm{a}), \mathrm{OH}^{*}$ profiles at identical temperature with pressures around $10 \mathrm{~atm}$ and $2 \mathrm{~atm}$ and for similar ignition delay times (corresponding to a higher temperature of $1226 \mathrm{~K}$ for the $2 \mathrm{~atm}$ case) are visible. As can be seen, the shapes of the profiles are somewhat similar regardless of the pressure or the temperature. However, for the high-pressure case the first peak is smaller and the ignition peak is narrower. The experiments were selected in similar fashion for a stoichiometric mixture diluted in $98 \% \mathrm{Ar}(\mathrm{b})$. In this case, both the first and ignition peaks have the same intensity for each pressure and temperature. Finally, a mixture at $\phi=0.5,98 \% \mathrm{Ar}$ and at the same temperature $(1371 \mathrm{~K})$ was investigated at around 2 and $34 \mathrm{~atm}$ (c). As can be seen, the first peak has the highest intensity for the high-pressure case, whereas the highest intensity corresponds to the ignition peak at $2 \mathrm{~atm}$. Note that the difference is not large, especially given the large pressure difference between the two profiles. 


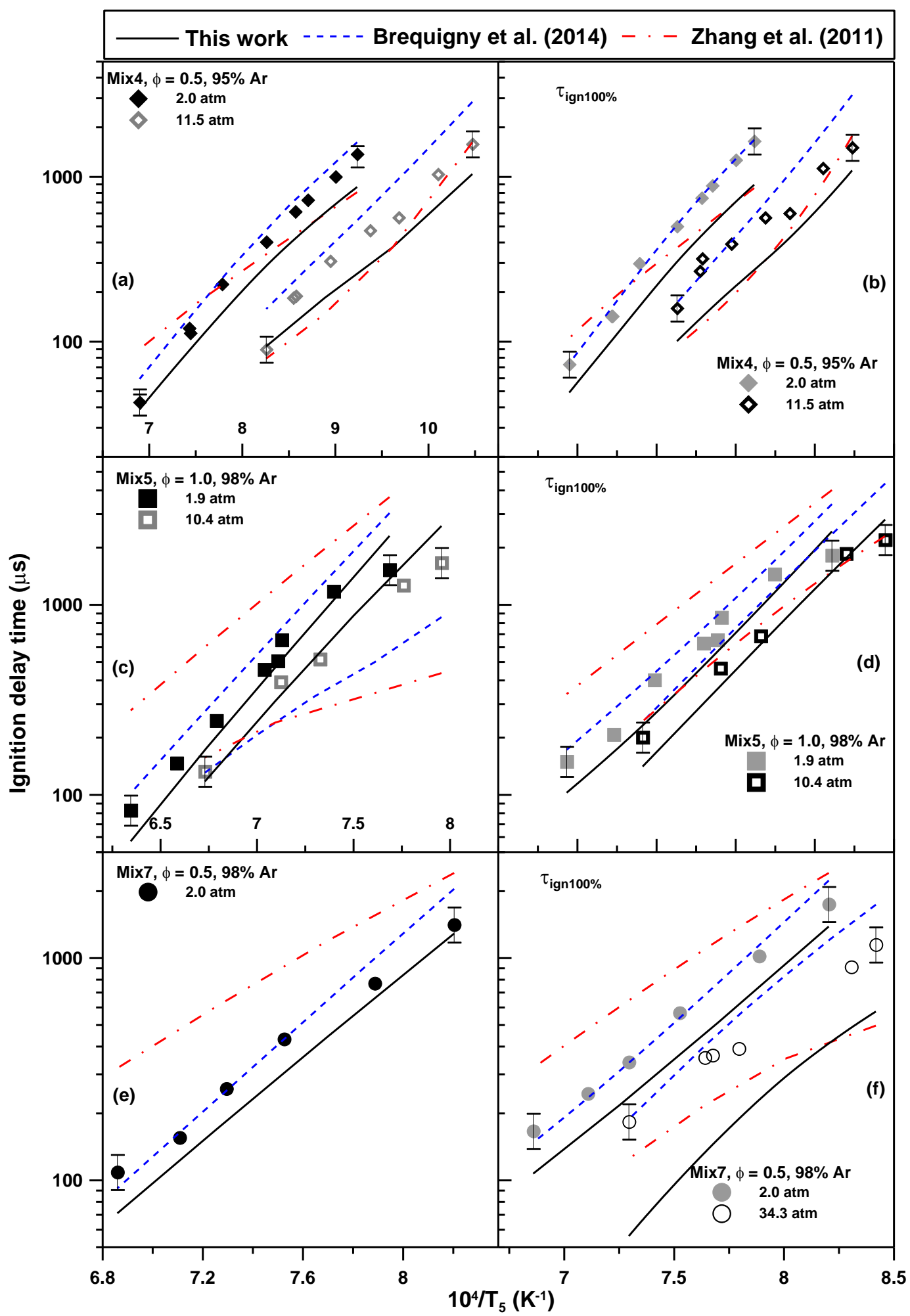

Figure 6: Effect of the pressure on the ignition delay time of $\mathrm{NM}$ for $(\mathrm{a}, \mathrm{b})$ a mixture at $\phi=0.5$ diluted in $95 \% \mathrm{Ar},(\mathrm{c}, \mathrm{d})$ a mixture at $\phi=1.0$ diluted in $98 \% \mathrm{Ar}$, and (e, f) a mixture at $\phi=0.5$ diluted in $98 \%$ Ar. 


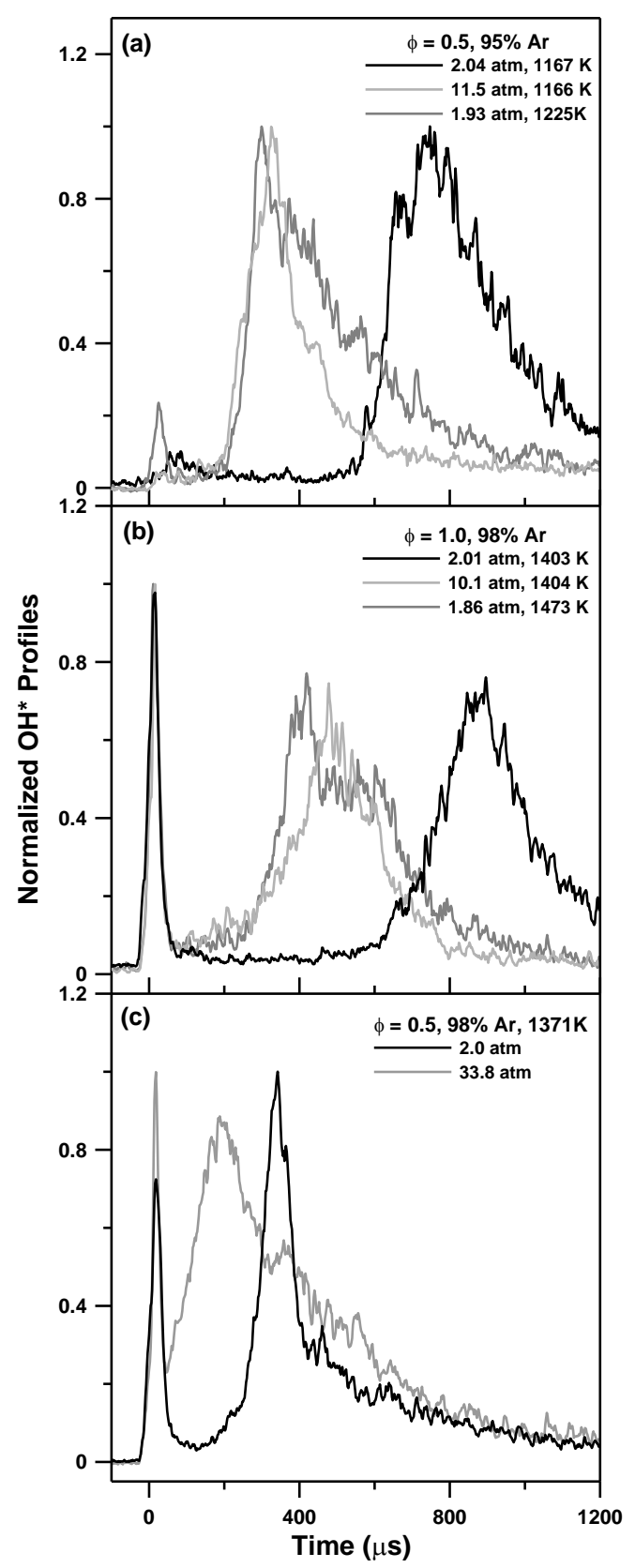

Figure 7: Evolution of the $\mathrm{OH}^{*}$ profile with the pressure (a) low- and high-pressure experiments at a similar temperature or a similar ignition delay time at $\phi=0.5,95 \%$ Ar, (b) a similar temperature or a similar ignition delay time at $\phi=1.0,95 \% \mathrm{Ar}$, and (c) a similar temperature $\phi=0.5,95 \% \mathrm{Ar}$.

\section{Dilution level effect}

The effect of the dilution level in Ar on the ignition delay time of NM can be seen in Fig. 8 for the lowpressure cases and in Fig. 9 for the intermediate-pressure cases. For nearly all conditions, the decrease in the dilution level leads to a decrease in the ignition delay time. This decrease seems however to be dependent on both the pressure and equivalence ratio. For the low-pressures cases, Fig. 8, the decrease in the ignition delay time is proportionally larger on the low-temperature side than on the high-temperature side. At $\phi=0.5$ (Fig. 8 
(a)), decreasing the dilution level from $98 \%$ to $90 \%$ of Ar significantly reduces the ignition delay time at around $1220 \mathrm{~K}$, from around $1400 \mu \mathrm{s}$ for Mix 7 (98\% Ar) to $400 \mu \mathrm{s}$ and $75 \mu$ s for Mix 4 (95\% Ar) and Mix 1 ( $90 \%$ Ar), respectively. The difference between the mixtures diminishes as the temperature increases, as the ignition delay time is around 2.5 times shorter for Mix 4 than for Mix 1 at around $1450 \mathrm{~K}$, with a factor of 3.5 at $1220 \mathrm{~K}$. A similar observation can be made for the ignition delay time determined at the maximum of the $\mathrm{OH}^{*}$ ignition peak (Fig. 8 (b)) and for the stoichiometric cases, Fig. 8 (c, d). As can be seen for the stoichiometric case, ignition delay times for the highly diluted mixtures (Mix 10, 99\% $\mathrm{Ar}$ ) are even lower than

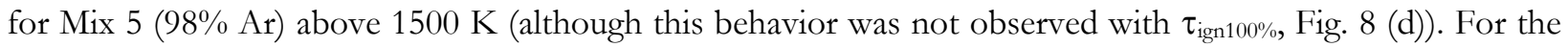
lowest temperature common to these three mixtures, $1340 \mathrm{~K}$, the ignition delay time decreases from around $2050 \mu$ s $\left(2200 \mu\right.$ s for $\tau_{\text {ign } 100 \%}$ ) (Mix 10, 99\% Ar) to around $1215 \mu$ s $\left(1530 \mu\right.$ s for $\tau_{\text {ign } 100 \%}$ ) (Mix 5, 98\% Ar) and around $370 \mu$ s (430 $\mu$ s for $\tau_{\text {ign } 100 \%)}$ (Mix 2, 95\% Ar).

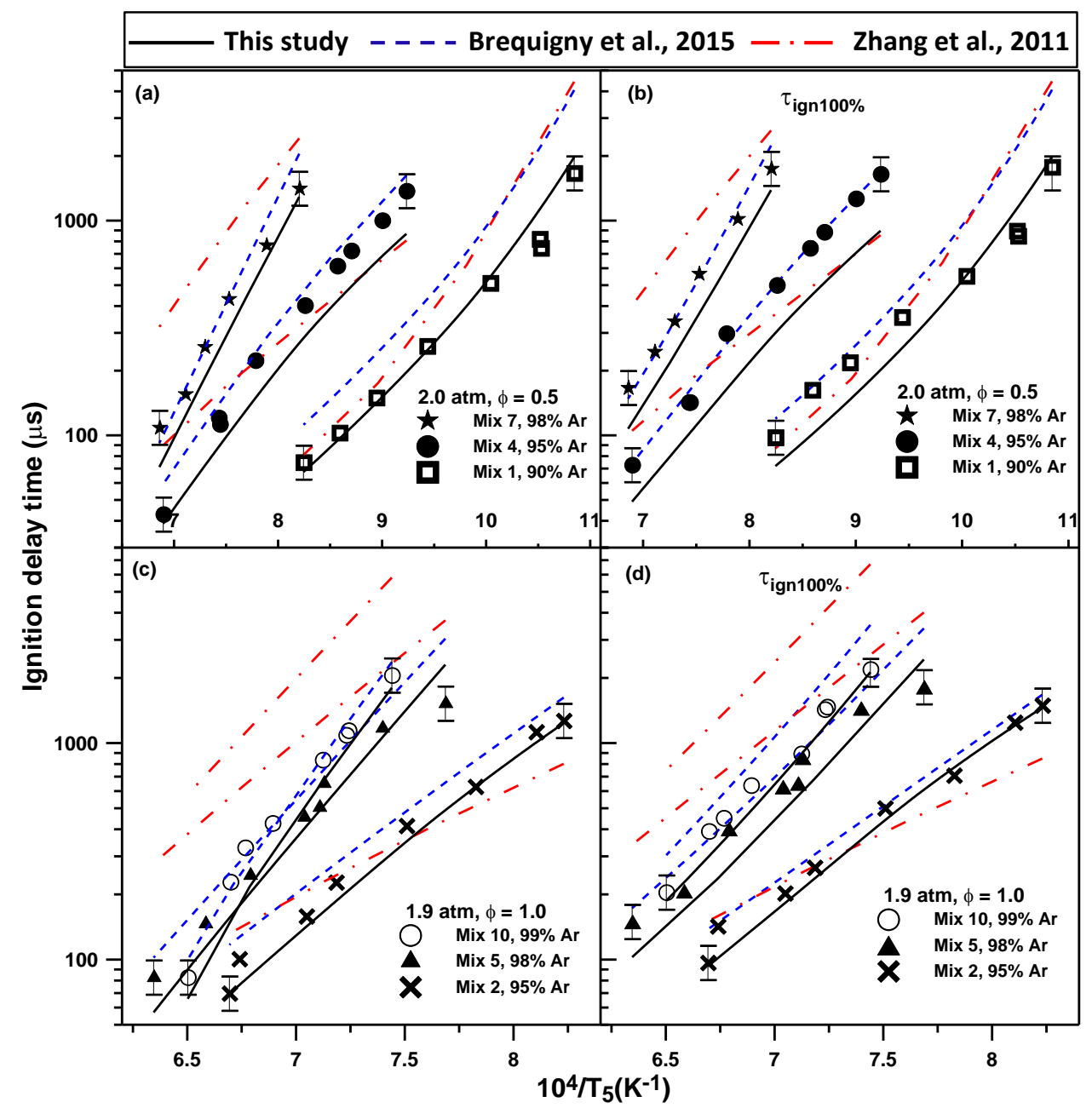

Figure 8: Effect of the dilution level in Ar on the ignition delay time of NM at around $2 \mathrm{~atm}$ for $(\mathrm{a}, \mathrm{b}) \phi=0.5$, and $(\mathrm{c}, \mathrm{d}) \phi=1.0$.

For the high-pressure case, Fig. 9, a very large difference can be observed for stoichiometric data (a, b), between Mix $5(98 \%$ Ar) and Mix $8(90 \%$ Ar). Note that the two sets of data do not overlap in terms of temperatures within the range of possible observation test times. On the other hand, data at fuel rich 
conditions (Fig. 9 (c, d)) are very close to each other despite the change in dilution level $(90 \%$ Ar for Mix 6 and $95 \%$ Ar for Mix 9). Note that this small difference can also be partly due to the difference in pressure between the two sets of data, around 8.6 atm for Mix 6 and around $13.7 \mathrm{~atm}$ for Mix 9.

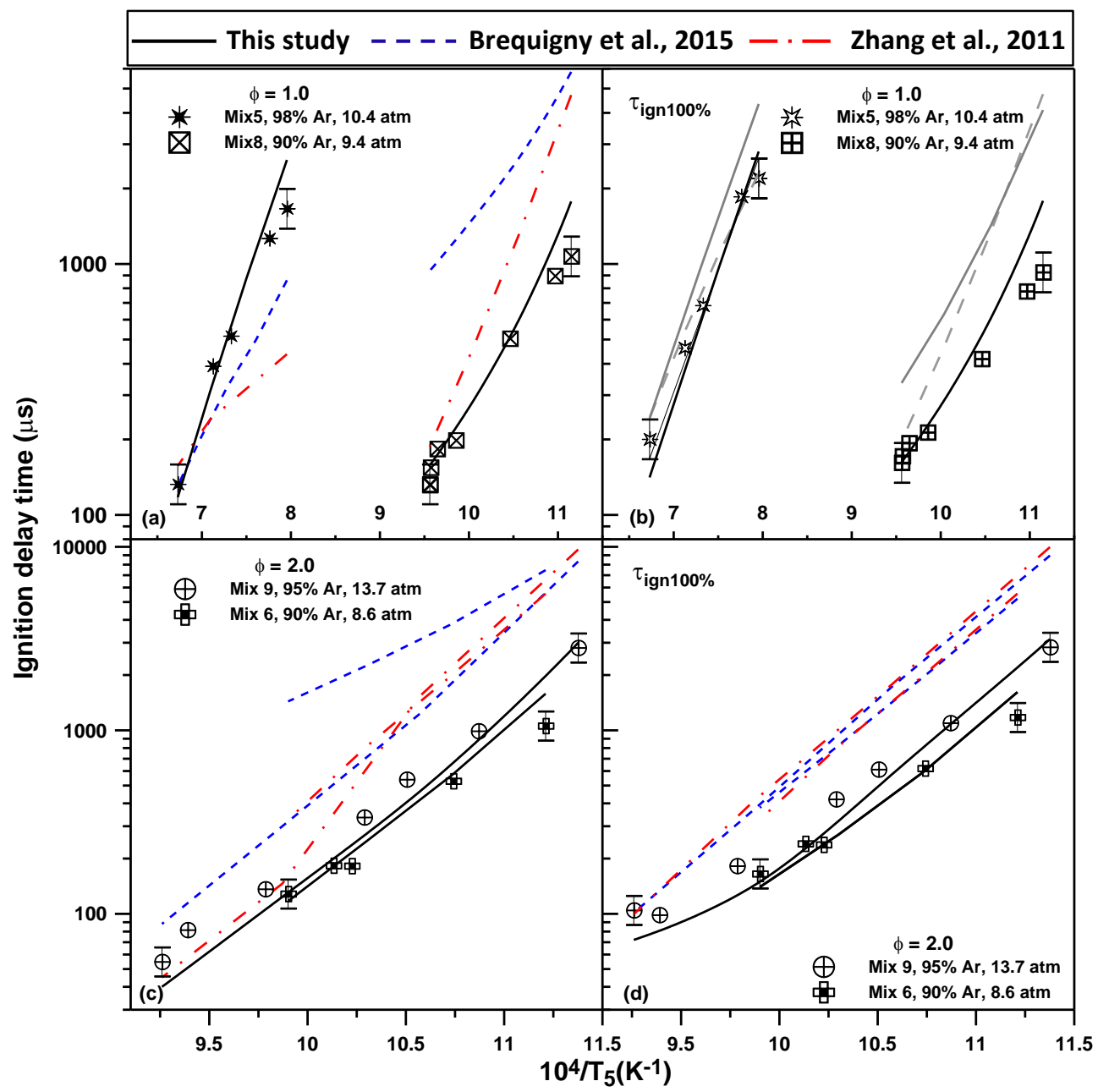

Figure 9: Effect of the dilution level in Ar on the ignition delay time of NM at around $10 \mathrm{~atm}$ for $(\mathrm{a}, \mathrm{b}) \phi=$ 1.0 , and $(\mathrm{c}, \mathrm{d}) \phi=2.0$.

The effect of the Ar dilution on the $\mathrm{OH}^{*}$ profiles is visible in Fig. 10 for mixtures at $\phi=0.5$ at around 2 atm for (a) similar temperatures $(1215 \pm 4 \mathrm{~K})$ and (b) similar ignition delay times. As can be seen in Fig. 10 (a), the highest intensity in the $\mathrm{OH}^{*}$ signal is reached by the ignition peak for all Ar concentrations investigated. However the intensity of the first peak varies greatly with the dilution level. The intensity of the first peak is less than 5\% of the ignition peak for the $90 \%$ Ar case, and this ratio increases to 10\% and 85\% for the 95\% and 98\% Ar dilution cases, respectively. A similar trend is observed for the case where the profiles match a similar ignition delay time (Fig. 10 (b)). In that case, the first peak's intensity is around 4\%, $25 \%$, and $75 \%$ of the ignition peak for Ar concentrations of $90 \%, 95 \%$, and $98 \%$, respectively. One can therefore conclude that the intensity of the first peak with regard to the ignition peak increases with the Ar concentration (i.e. more dilution). 


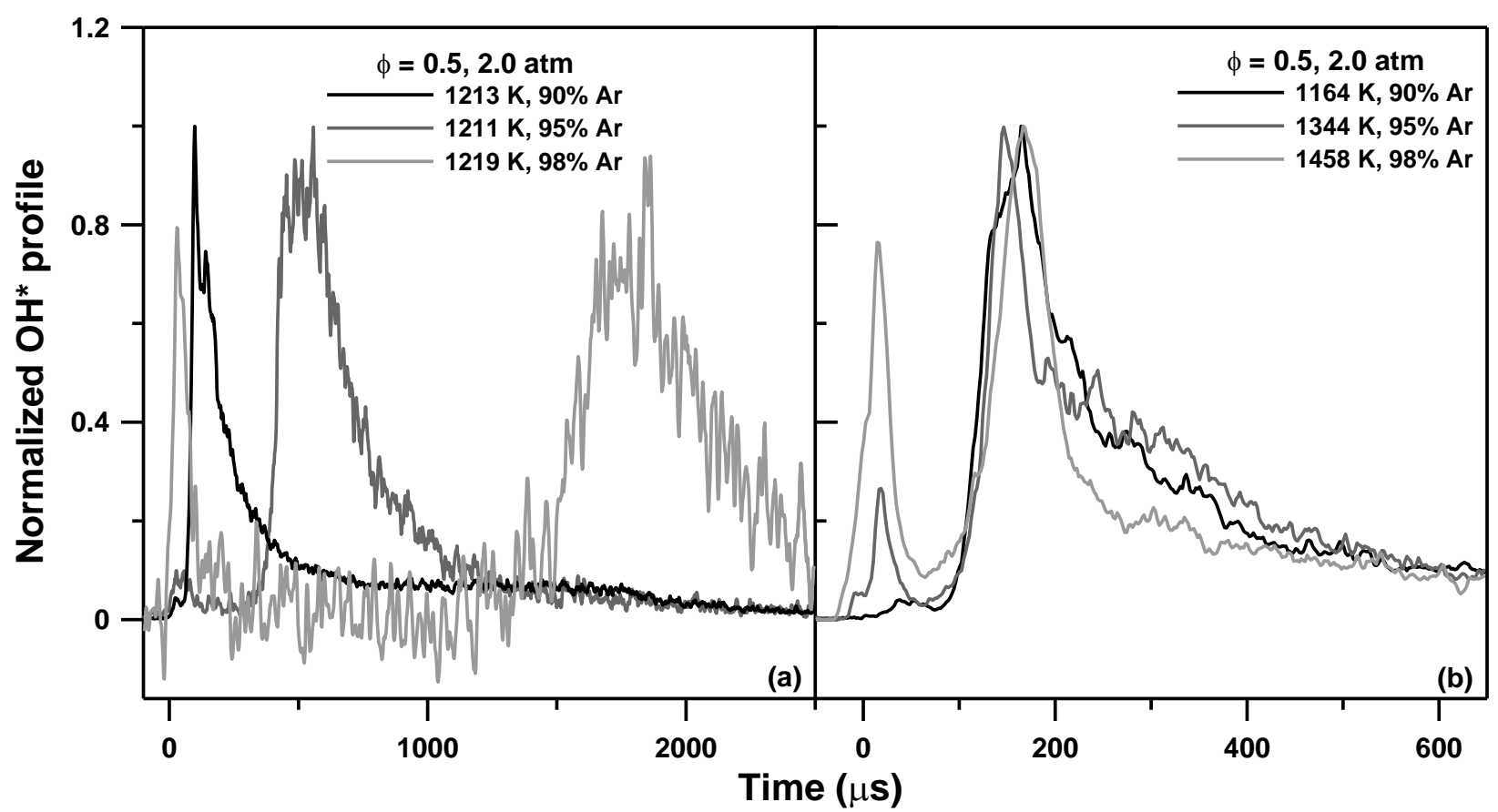

Figure 10: Evolution of the $\mathrm{OH}^{*}$ profile with time for (a) similar temperatures and (b) similar ignition delay times as a function of the dilution level in Ar for mixtures around $2 \mathrm{~atm}$ and for an equivalence ratio of 0.5.

During this study, an attempt was made to determine an ignition correlation for the data determined during this study. It was found that it was not possible to determine such correlation with an acceptable coefficient of correlation value when all the data were taken into account. Ignition correlations were however determined for each dilution level in Ar as can be seen below for the 98\% and 90\% Ar cases (note that these correlations have been determined using $\tau_{\text {ign } 100 \%}$ to incorporate the $30 \mathrm{~atm}$ data for the $98 \%$ Ar dilution case):

$$
\begin{aligned}
& \tau_{\text {ign } 100 \%}(\mu s)=1.228 \times 10^{-3} \varphi^{1.55} P^{-0.26} \exp (37.5 / R T) \quad\left(98 \% \mathrm{Ar}, \mathrm{r}^{2}=0.98\right) \\
& \tau_{\text {ign } 100 \%}(\mu s)=1.591 \times 10^{-2} \varphi^{-0.72} P^{0.06} \exp (19.8 / R T) \quad\left(90 \% \mathrm{Ar}, \mathrm{r}^{2}=0.95\right)
\end{aligned}
$$

In the above correlations, $\mathrm{P}$ is in atm, the ignition activation energy in the exponential term is in $\mathrm{kcal} / \mathrm{mol}, \mathrm{R}$ is the universal gas constant in $\mathrm{kcal} / \mathrm{mol}-\mathrm{K}$ units, and $\mathrm{T}$ is the temperature in $\mathrm{K}$. As one can see, the value of the exponent for the equivalence ratio changes from positive (ignition delay time increases as the equivalence ratio increases) to negative when the dilution level decreases from $98 \%$ to $90 \%$ Ar. An opposite trend is observed with the exponent over the pressure. In addition, there is a marked difference in ignition activation energy $(19.8$ to $37.5 \mathrm{kcal} / \mathrm{mol})$. This behavior explains why it was not possible to obtain a single ignition correlation for all the data measured in this study, which is not unexpected when looking at ignition delay times over such a wide range of dilution and variation in kinetic behavior [36]. However, the detailed kinetics model is able to replicate the complicated behavior changes over the entire range of experimental conditions, as presented next. 


\section{Modeling}

4.1 Description of the models used

Data from this study were compared to models from the literature. Four models from the literature were considered, although the results from the models from Boyer and Kuo [4] and Tian et al. [14] are not reported in this paper due to their relatively poor performance (ignition delay times are too long by more than an order of magnitude for most of the conditions). The ignition delay time predictions for the more-recent models from Zhang et al. [14] and Brequigny et al. [3] are visible in Figs. 4, 6, 8, and 9. These mechanisms were compared to a mechanism proposed in the present study. The proposed mechanism is based on the recent incremental work by the authors on $\mathrm{H}_{2} / \mathrm{N}_{2} \mathrm{O}$ [37], $\mathrm{H}_{2} / \mathrm{NO}_{2}$ [38], $\mathrm{NH}_{3} / \mathrm{NO} / \mathrm{N}_{2} \mathrm{O}$ [26], and $\mathrm{CH}_{4} / \mathrm{NO}_{2} / \mathrm{N}_{2} \mathrm{O}$ [27] (this work being largely based on literature mechanisms [39-43]) and has been extended with the NM sub-mechanisms from Brequigny et al. [3] and some reactions from the recent study of Annesley et al. [22]. Specifically, the recent decomposition rates for nitromethane $\left(\mathrm{CH}_{3} \mathrm{NO}_{2} \leftrightarrows \mathrm{CH}_{3}+\mathrm{NO}_{2}\right.$ (R3) and $\mathrm{CH}_{3} \mathrm{NO}_{2} \leftrightarrows \mathrm{CH}_{3} \mathrm{O}+\mathrm{NO}$ (R4)) were adopted from Annesley and coworkers. It is important to mention here that the values of $k_{R 3}$ and $k_{R 4}$ reported in Annesley et al. are based on theoretical computations with $\mathrm{Kr}$ as bath gas. According to the principal investigators of the study from Annesley et al., Dr. Tranter and Dr. Klippenstein (private communication), the difference in energy transfer between $\mathrm{Kr}$ and $\mathrm{Ar}$ induces different values for $k_{R 3}$ and $k_{R 4}$. Therefore, their values for $k_{R 3}$ and $k_{R 4}$ calculated by Dr. Klippenstein with $A r$ as bath gas were used in this study. These reaction rates are shown in the present paper in Table 3, and the full, detailed kinetics mechanism and its associated thermodynamic data are available as supplementary material.

All the reactions involving the $\mathrm{H}_{2} /$ hydrocarbons / $\mathrm{O}_{2}$ sub-systems in the final mechanism come from the initial model of Metcalfe et al. [39]. In case of duplicate reactions for the NM/NOx sub-system, the reactions from Mathieu et al. [27] were kept, except for the reactions listed in Table 3. The final mechanism is comprised of 166 species and 1204 reactions. Note that these additions to the $\mathrm{CH}_{4} / \mathrm{NOx}$ mechanism of Mathieu et al. [27] slightly modify its reactivity for $\mathrm{CH}_{4} / \mathrm{NOx}$ data but do not deteriorate the good agreement reached with literature data in Mathieu et al. [27], as is shown later. All calculations shown in figures in this study were performed using the Chemkin Pro software [44]. The "brute force" calculations discussed later were performed using Cantera [45]. 
Table 3: Reaction rates adopted from Brequigny et al. [3] and Annesley et al. [22] for the cases of duplicate reactions with the model of Mathieu et al. [27] and for the thermal decomposition of nitromethane in Ar as determined theoretically by Annesley et al. [22]. The rate coefficient of each reaction is of the form $\mathrm{k}=\mathrm{A} \mathrm{T}^{\mathrm{n}}$ $\exp (-\mathrm{Ea} / \mathrm{RT})$, and units are calories, $\mathrm{cm}^{3}$, mol, seconds.

\begin{tabular}{|c|c|c|c|c|}
\hline \multirow{2}{*}{ Reaction } & \multicolumn{3}{|c|}{ Reaction rate } & \multirow{2}{*}{ Source } \\
\hline & A & $\mathrm{n}$ & $\mathrm{Ea}$ & \\
\hline $\mathrm{HCO}+\mathrm{NO} \leftrightarrows \mathrm{HNO}+\mathrm{CO}$ & $1.0 \times 10^{8}$ & 1.5 & -1760 & [46] \\
\hline $\mathrm{CH}_{3}+\mathrm{NO}_{2} \leftrightarrows \mathrm{CH}_{3} \mathrm{O}+\mathrm{NO}$ & $4.0 \times 10^{13}$ & -0.2 & 0 & [13] \\
\hline $\mathrm{CH}_{3} \mathrm{NO}_{2}+\mathrm{OH} \leftrightarrows \mathrm{CH}_{2} \mathrm{NO}_{2}+\mathrm{H}_{2} \mathrm{O}$ & $5.0 \times 10^{5}$ & 2 & 1000 & [13] \\
\hline $\mathrm{HNO}+\mathrm{M} \leftrightarrows \mathrm{H}+\mathrm{NO}+\mathrm{M}$ & $1.26 \times 10^{16}$ & -0.43 & 49480 & [13] \\
\hline \multicolumn{4}{|l|}{$\mathrm{CH}_{3} \mathrm{NO}_{2} \leftrightarrows \mathrm{CH}_{3}+\mathrm{NO}_{2}$} & \multirow[t]{11}{*}{ [22] } \\
\hline $0.1 \mathrm{~atm}$ & $5.176 \times 10^{48}$ & -10.855 & 67468 & \\
\hline $0.2 \mathrm{~atm}$ & $4.875 \times 10^{48}$ & -10.750 & 67689 & \\
\hline $0.5 \mathrm{~atm}$ & $2.649 \times 10^{48}$ & -10.545 & 67936 & \\
\hline $1 \mathrm{~atm}$ & $1.033 \times 10^{48}$ & -10.330 & 68069 & \\
\hline $2 \mathrm{~atm}$ & $2.393 \times 10^{47}$ & -10.050 & 68131 & \\
\hline $5 \mathrm{~atm}$ & $1.489 \times 10^{46}$ & -9.575 & 68083 & \\
\hline $10 \mathrm{~atm}$ & $9.506 \times 10^{44}$ & -9.135 & 67940 & \\
\hline $20 \mathrm{~atm}$ & $3.548 \times 10^{43}$ & -8.630 & 67701 & \\
\hline $50 \mathrm{~atm}$ & $2.399 \times 10^{41}$ & -7.885 & 67261 & \\
\hline $100 \mathrm{~atm}$ & $2.904 \times 10^{39}$ & -7.245 & 67799 & \\
\hline \multicolumn{4}{|l|}{$\mathrm{CH}_{3} \mathrm{NO}_{2} \leftrightarrows \mathrm{CH}_{3} \mathrm{O}+\mathrm{NO}$} & \multirow[t]{11}{*}{ [22] } \\
\hline $0.1 \mathrm{~atm}$ & $2.851 \times 10^{48}$ & -11.020 & 66953 & \\
\hline $0.2 \mathrm{~atm}$ & $1.644 \times 10^{48}$ & -10.880 & 67057 & \\
\hline $0.5 \mathrm{~atm}$ & $4.932 \times 10^{47}$ & -10.635 & 67138 & \\
\hline $1 \mathrm{~atm}$ & $4.932 \times 10^{47}$ & -10.635 & 67138 & \\
\hline $2 \mathrm{~atm}$ & $2.333 \times 10^{46}$ & -10.110 & 67089 & \\
\hline $5 \mathrm{~atm}$ & $1.349 \times 10^{45}$ & -9.660 & 66924 & \\
\hline $10 \mathrm{~atm}$ & $1.002 \times 10^{44}$ & -9.265 & 66722 & \\
\hline $20 \mathrm{~atm}$ & $6.266 \times 10^{42}$ & -8.850 & 66507 & \\
\hline $50 \mathrm{~atm}$ & $6.266 \times 10^{42}$ & -8.850 & 66507 & \\
\hline $100 \mathrm{~atm}$ & $9.078 \times 10^{39}$ & -7.875 & 66229 & \\
\hline
\end{tabular}

\subsection{Comparison with the Ignition Delay Time Data}

As can be seen in Fig. 4 for the equivalence ratio effect at around $1.9 \mathrm{~atm}(98 \% \mathrm{Ar})$, the model of Zhang et al. [14] predicts ignition delay times that are significantly too long, especially for the high-temperature side (up to a factor 4), and the ignition activation energy that can be extracted from the experimental data in Fig. 4 is significantly higher than the activation energy predicted by this model. In comparison, the model from Brequigny et al. is significantly more accurate, with activation energies that are relatively close to the experimental ones. Predictions with the model of Brequigny et al. are generally within reasonable agreement with the data (usually within a factor of around 1.5), except for the fuel rich case at low temperatures where a factor of up to 2 is observed. Results for the fuel-lean mixture are well predicted, especially for the time at which the maximum of the $\mathrm{OH}^{*}$ signal is reached. Ignition delay times predicted by the model of the present study are more accurate for the fuel-rich condition, notably for the $\tau_{\text {ign } 100 \%}$ case. Stoichiometric results are also slightly better predicted (within 25\%), especially for the low-temperature side, but the computed results at $\phi=$ 0.5 show an ignition delay time that is too short, by a factor up to 1.5 at high temperatures. 
The modeling of the pressure effects on Mix 4, 5, and 7 is visible in Fig. 6. Note that the low-pressure data with Mix 5 and 7 have been discussed previously, and Fig. 4 shows the ignition delay time is poorly predicted by the model of Zhang et al. at all conditions investigated except for the Mix 4 results at around 10 atm (Fig. 6 (a and b)). The mechanism of Brequigny et al. presents fair accuracy for all conditions. The mechanism of the present study offers good predictions for all conditions except $30 \mathrm{~atm}$, where the model is over-reactive (a difference by a factor up to 2.5 can be observed with the data). Fuel-lean mixtures are slightly too reactive with the model of the present study, in general.

The modeling of the effect of the dilution level at low pressure is visible in Fig. 8. The less-dilute mixtures are particularly well predicted by the model from the present study, especially when compared to the models from the literature. At $\phi=1.0$ (Fig. 8 (c)), it is worth noting that at $99 \%$ Ar ignition delay times are shorter than at $98 \%$ at high temperatures. This behavior is picked up by the model of Brequigny et al. and the model from the present study. For the high-pressure cases, Fig. 9, one can see that the predictions from the model proposed in this study are far superior to the other models and match experiments at all conditions, whereas the other models, including Brequigny et al., are significantly over-predicting the ignition delay time (up to a factor of 10 at high temperatures, Fig. 9 (a) and (c)).

\subsection{Comparison with $\mathrm{OH}^{*}$ profiles}

For all the models considered and for most of the conditions investigated, the first peak of $\mathrm{OH}^{*}$ formation near time zero is overestimated, sometimes by more than two orders of magnitude. It is worth mentioning that this level of discrepancy goes much beyond the uncorrected numerical profiles for the first peak, where a correction would be required to account for the time response of the experimental data near time zero as mentioned above. It can be concluded that, since the formation of $\mathrm{OH}^{*}$ occurs almost exclusively from the reaction $\mathrm{CH}+\mathrm{O}_{2} \leftrightarrows \mathrm{OH}^{*}+\mathrm{CO}$ for the present conditions, this discrepancy between the models and the experiments is mainly due to the numerical predictions for the amount of $\mathrm{CH}$ radicals formed. This is something that would need to be addressed but is beyond the scope of the present paper.

Consequently to this numerical over-prediction, a direct comparison between the computed and experimental profiles is impossible. One possible way to observe the performance of the models at predicting the $\mathrm{OH}^{*}$ profiles is to determine the ratio between the intensity of the first peak and the intensity of the ignition peak for each model. This ratio was then normalized to the highest ratio determined for each model. A similar procedure was followed with the experimental profiles. Due to the uncorrected experimental profiles and very large over-estimation of the first peak intensity from the models, only qualitative information can be obtained from these figures, and results are visible in the supplementary material section. As can be seen, all the trends observed experimentally are predicted by the models.

\subsection{Comparison with literature data}

To further test the current model, data available in the literature were also analyzed. Literature results were also compared to the predictions from the model of Brequigny et al. and, whenever possible (pyrolysis), to the model from Annesley et al. [22]. The model from Zhang et al. [14] was not considered for data other than decomposition profiles of NM, due to its poor performance against most of the ignition delay time data from the present study, as seen before.

Figure 11 presents the comparison between the evolution of the $\mathrm{NM}$ and $\mathrm{NO}_{2}$ profiles from a highly diluted mixture of NM in Ar at $1180 \mathrm{~K}$ and $5.95 \mathrm{~atm}$ from Gläntzer and Troe [47]. As can be seen, the NM profile is fairly well reproduced from all the models, as a nearly identical NM profile was yielded by the mechanisms. This result indicates that the latest theoretical work on nitromethane decomposition by Annesley et al. is giving satisfactory results. 
The $\mathrm{NO}_{2}$ profile in Fig. 11 is also relatively well predicted by the 4 models: the $\mathrm{NO}_{2}$ peak is predicted with accuracy by all the models within $5 \%$ of the maximum value; but differences can be observed after that. The model of Zhang et al. reproduces with accuracy the experimental trend and the amount of $\mathrm{NO}_{2}$ formed whereas the other models are within $25 \%$ of the experimental value.

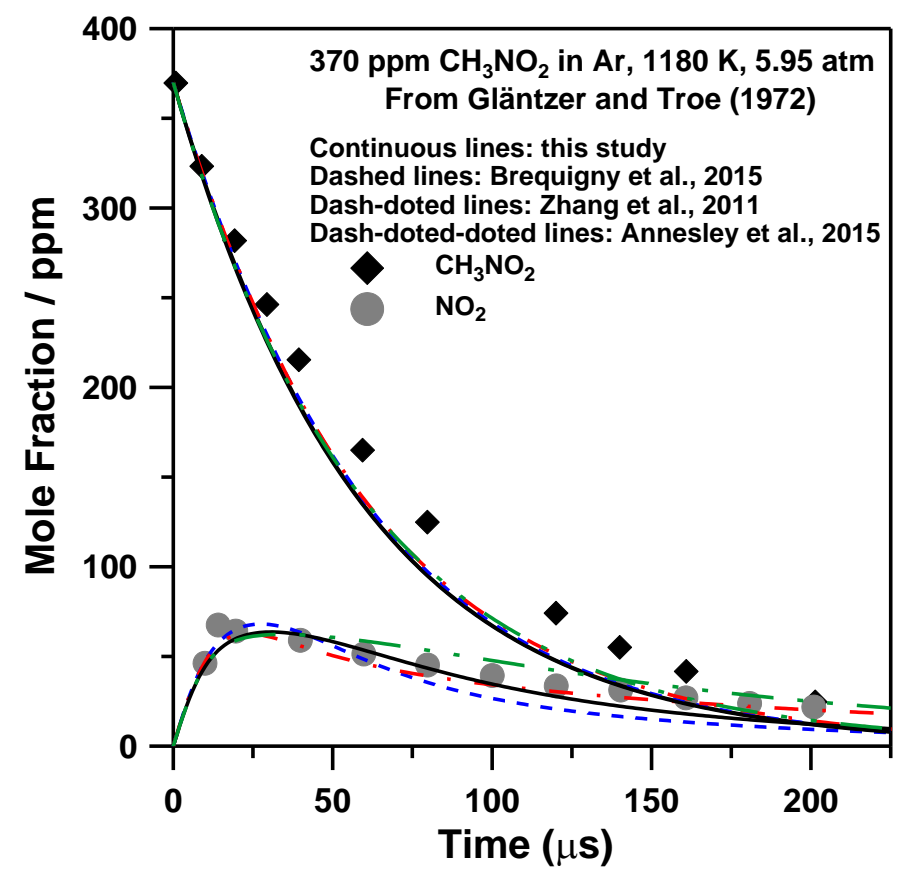

Figure 11: Comparison between nitromethane models (this study, Brequigny et al. [3], Annesley et al. [22] and Zhang et al. [14]) and the data from Gläntzer and Troe [47].

Hsu and Lin [48] measured by laser absorption the time evolution of CO and NO concentrations from diluted mixtures of NM in a shock tube. Various dilution levels at sub-atmospheric pressures were investigated. As can be seen in Fig. 12, for a NM concentration of $0.25 \%$ in Ar, the NO and CO profiles are largely under-predicted (predicted values are 50-55\% lower than the experimental values) by both the model of this study and the model from Brequigny et al.. In comparison, the model from Annesley et al. predicts the NO profile with good agreement, whereas CO is still under-predicted by up to $35 \%$. 


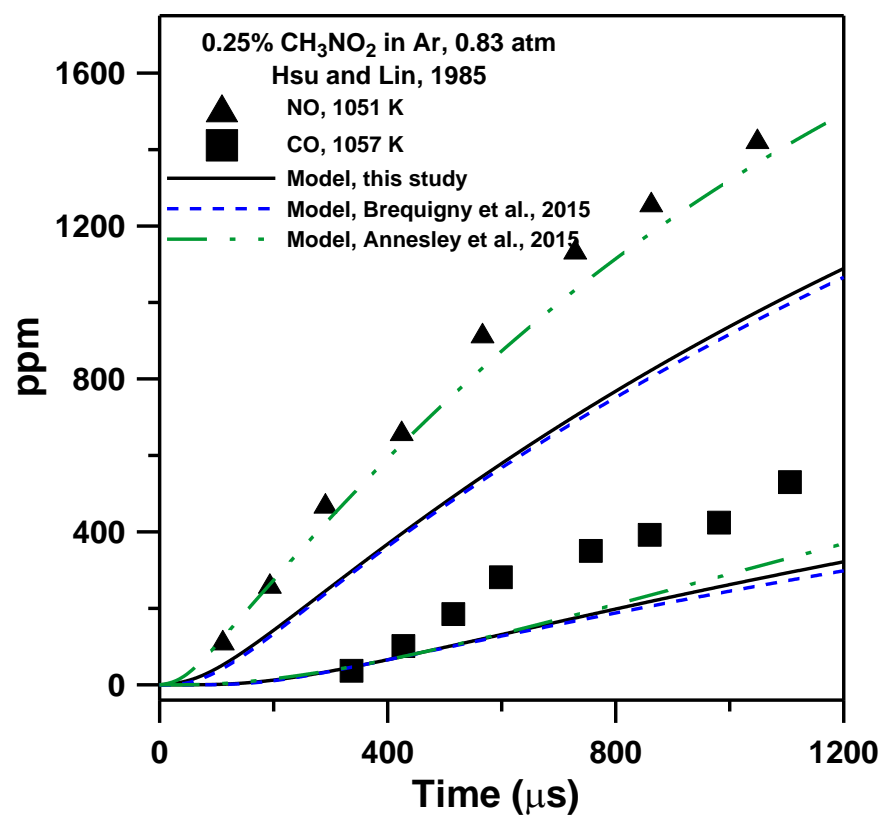

Figure 12: Comparison between nitromethane models (this study, Brequigny et al. [3] and Annesley et al. [22]) and the NO and CO profiles from Hsu and Lin [48] (0.25\% NM in Ar, $0.83 \mathrm{~atm}$ and around $1055 \mathrm{~K})$.

For a larger concentration of NM ( $0.4 \%$ in Ar, Fig. 13), the models are in better agreement with the experimental data. The $\mathrm{CO}$ profile is a bit underestimated by the model from the present study (by less than 20\%), whereas the models from Annesley et al. slightly over-predict the amount of CO formed (within 10\%). Brequigny et al. under-predicts the $\mathrm{CO}$ concentration a bit more than the model of the present study, by up to $30 \%$. The final amount of NO formed is over-estimated by all the models by around $20 \%$ but is predicted with fair accuracy by both this study and Brequigny et al. up to around $45 \mu$ s.

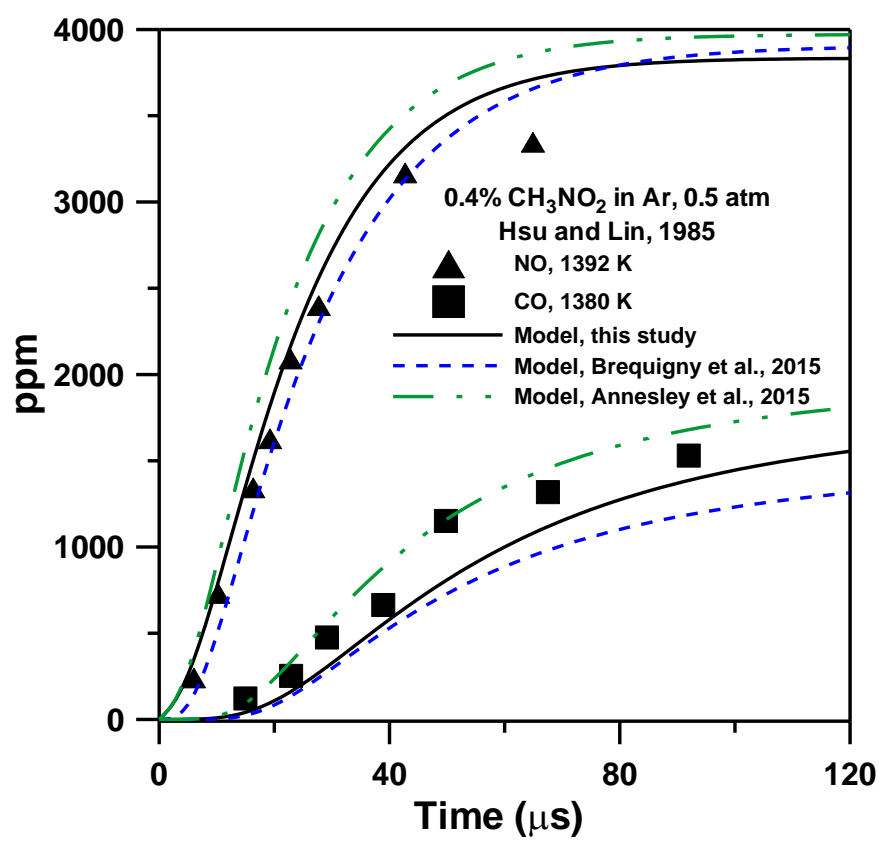

Figure 13: Comparison between nitromethane models (this study, Brequigny et al. [3] and Annesley et al. [22]) and the $\mathrm{NO}$ and $\mathrm{CO}$ profiles from Hsu and Lin [48] (0.4\% NM in Ar, $0.5 \mathrm{~atm}$ and around $1386 \mathrm{~K})$. 
At the largest $\mathrm{NM}$ concentration $(0.76 \%$ in $\mathrm{Ar})$ investigated by Hsu and Lin, Fig. 14, the NO profile is relatively well predicted, and CO under-predicted, by the present study and Brequigny et al. (around 30\% under-prediction), while Annesley et al. over-predicts NO by up to $20 \%$ but predicts CO well.

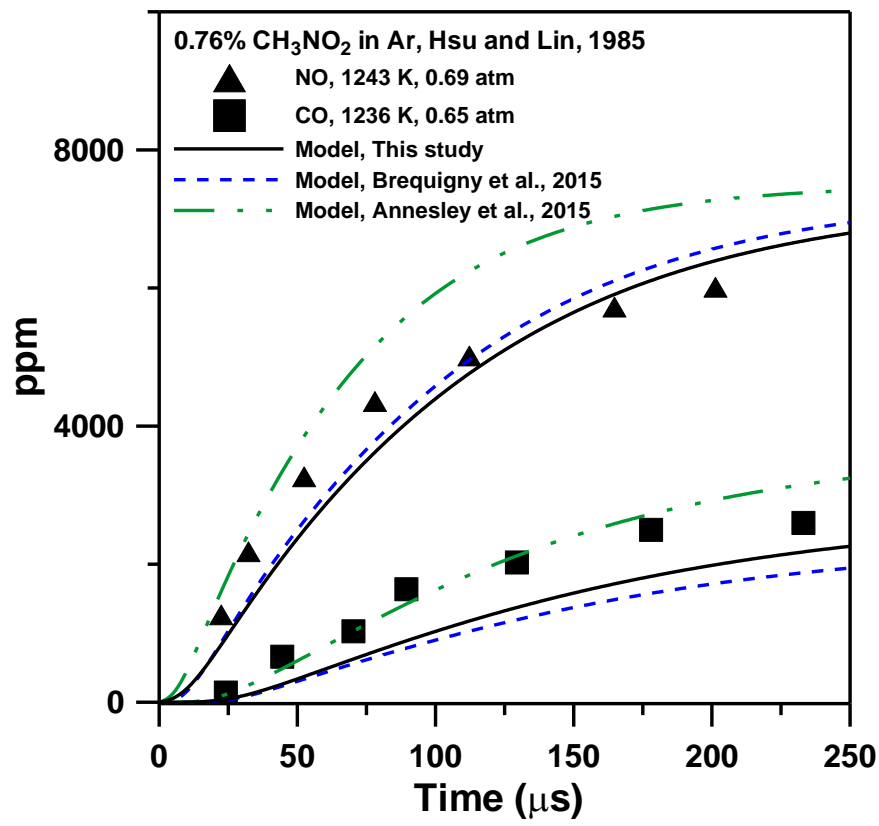

Figure 14: Comparison between nitromethane models (this study, Brequigny et al. [3] and Annesley et al. [22]) and the NO and CO profiles from Hsu and Lin [48] (0.76\% NM in Ar, around 0.67 atm and $1240 \mathrm{~K})$.

Zhang and Bauer [49] determined the amount of (a) $\mathrm{CH}_{3} \mathrm{NO}_{2}$, (b) $\mathrm{CH}_{4}$, (c) $\mathrm{C}_{2} \mathrm{H}_{4}$, and (d) $\mathrm{C}_{2} \mathrm{H}_{6}$ as a function of temperature behind reflective shock waves for a mixture of $0.67 \% \mathrm{NM}$ in Ar (Fig. 15). These components were quantified by gas chromatography of gas sampled right after the RSW. To model these data, the mechanisms (this study, Brequigny et al., Annesley et al.) were used at the average pressure of 4.75 atm, and computed values were taken for a test time of $1.5 \mathrm{~ms}$, as in Zhang et al. [15]. As can be seen in Fig. 15 (a), the NM profile is relatively well reproduced by all the models from this study, although differences between the models are visible. The methane profile (Fig. 15 (b)) is significantly over-predicted by around $50 \%$ at high temperature by the model from Annesley and coworkers. The $\mathrm{CH}_{4}$ profile is also over-predicted by the other models, but by less than $20 \%$ above $1080 \mathrm{~K}$. Finally, the largest difference between the models is observed for the $\mathrm{C}_{2} \mathrm{H}_{4}$ (Fig. 15 (c)) and $\mathrm{C}_{2} \mathrm{H}_{6}$ (Fig. 15 (d)) profiles. The model from Annesley et al. significantly under-predicts the amount of $\mathrm{C}_{2} \mathrm{H}_{4}$ by a factor up to 5 , whereas an under-prediction by less than $30 \%$ is observed for the model of the present study. The model of Brequigny et al. is the only model to overpredict the amount of ethylene, by $45 \%$ at most. The three models predict the shape of the $\mathrm{C}_{2} \mathrm{H}_{6}$ profile but ethane is over-predicted in all case at low temperature, from a factor 1.3 (Annesley et al.) to nearly 2 (this study). On the high temperature side, the model of Annesley et al. under-predict the amount of $\mathrm{C}_{2} \mathrm{H}_{6}$ by around $20 \%$ whereas the other models over-estimate it by up to $33 \%$ for the model of the present study. 


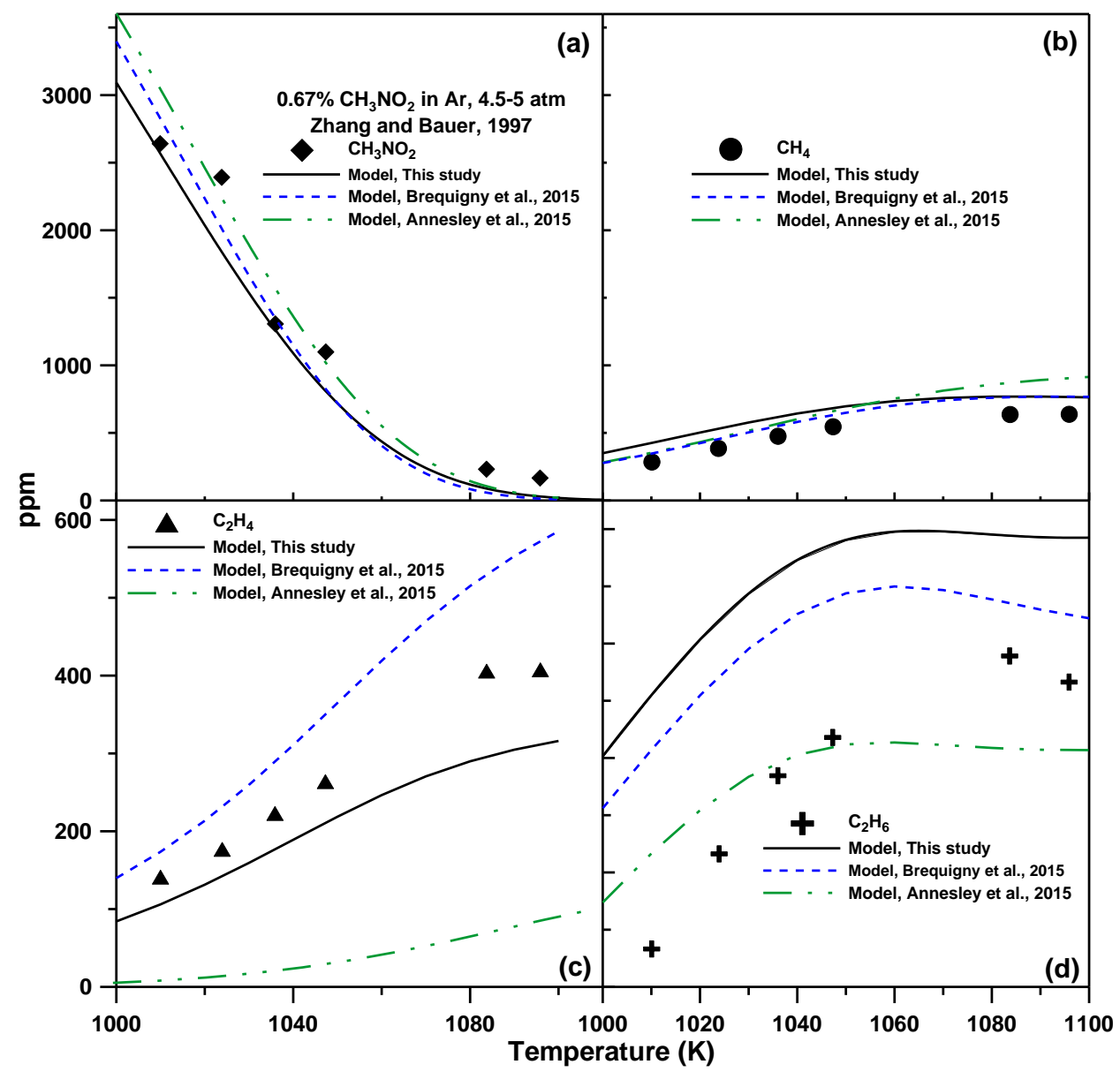

Figure 15: Comparison between nitromethane models (this study, Brequigny et al. [3] and Annesley et al. [22]) and the $\mathrm{CH}_{3} \mathrm{NO}_{2}$ (a), $\mathrm{CH}_{4}$ (b), $\mathrm{C}_{2} \mathrm{H}_{4}$ (c), and $\mathrm{C}_{2} \mathrm{H}_{6}$ (d) profiles as a function of temperature from Zhang and Bauer [49].

As mentioned before, the present model uses the $\mathrm{CH}_{4} / \mathrm{NOx}$ mechanism presented in Mathieu et al. [27]. To make sure that the modifications made for the nitromethane model do not adversely modify the predictions of the original mechanism, some representative data from the former $\mathrm{CH}_{4} / \mathrm{NOx}$ study [27] have been modeled with the NM models from this study and from Brequigny et al. for comparison. Results are visible in the Supplementary Material Section and show that these experiments are accurately reproduced by the model from the present study.

\section{5-Discussion}

Prior to the present study, no ignition delay time data were available to assess the overall validity of detailed kinetics mechanisms for nitromethane. This study observed important differences between mechanisms' predictions, even for recent models such as Zhang et al. (2011) and Brequigny et al. (2015). To help explain these differences, sensitivity and reaction pathway analyses were performed using the model of the present study, the model of Zhang et al., the model of Brequigny et al. and, whenever possible, the model of Annesley and coworkers. The sensitivity analysis was performed on $\mathrm{OH}^{*}$ using the Chemkin Pro software [44]. The validity of the sensitivity analysis for ignition delay time using $\mathrm{OH}^{*}$ was validated in Mathieu et al. [38] by comparing results with a "brute force" sensitivity analysis for mixtures of $\mathrm{H}_{2} / \mathrm{O}_{2}$ seeded with $\mathrm{NO}_{2}$ and diluted in Ar. A "brute force" method was also performed during this study using an earlier version of 
the current mechanism (prior to adding the NM dissociation pathways from Annesley et al. [22]) in which the effect on calculated ignition time was determined due to doubling the rate of one reaction in the mechanism, for 24 different reactions, for every experiment. The 24 reactions were chosen from examining $\mathrm{H}$-atom and $\mathrm{CH}_{3}$ sensitivity coefficient plots for a number of experiments. There is very strong correlation between the relative importance of reactions from the $\mathrm{OH}^{*}$ sensitivity and the relative importance of the rate coefficients of reactions on calculated ignition times in the "brute force" analysis.

Due to the large ranges of conditions covered in this study in terms of equivalence ratios, dilution levels, pressures and temperatures, results from the two sensitivity analysis methods show that the reactions that most influence ignition delay time vary depending on experimental conditions. Calculated ignition delay times are much more sensitive to the rates of the dissociation reactions of $\mathrm{NM}\left(\mathrm{CH}_{3} \mathrm{NO}_{2} \leftrightarrows \mathrm{CH}_{3}+\mathrm{NO}_{2}\right.$ (R1) and $\mathrm{CH}_{3} \mathrm{NO}_{2} \leftrightarrows \mathrm{CH}_{3} \mathrm{O}+\mathrm{NO}(\mathrm{R} 3)$ ) than other reactions at low temperatures (below $1000 \mathrm{~K}$ ), and at even higher temperatures for fuel rich mixtures (mixture 9). At all other conditions, calculated ignition delay times are much more sensitive to the rate of $\mathrm{H}+\mathrm{O}_{2} \leftrightarrows \mathrm{OH}+\mathrm{O}$ (R4) than any other reaction, especially in lean and highly diluted mixtures (mixtures 4, 7, and 10). It is interesting to note that above $1000 \mathrm{~K}$, changes in the rate coefficient of the reaction $\mathrm{R} 2\left(\mathrm{CH}_{3}+\mathrm{NO}_{2} \leftrightarrows \mathrm{CH}_{3} \mathrm{O}+\mathrm{NO}\right)$ causes a significantly larger impact than changes in the rates of the initial dissociation reactions. There are a handful of experiments (higher temperatures, stoichiometric, low pressure) at which $\mathrm{HCO}$ reactions ( $\mathrm{HCO}+\mathrm{M} \leftrightarrows \mathrm{H}+\mathrm{CO}+\mathrm{M}$ (R5), $\mathrm{HCO}+\mathrm{NO} \leftrightarrows$ $\mathrm{HNO}+\mathrm{CO}(\mathrm{R} 6)$ ) become very important due to their effect on $\mathrm{H}$-atom concentrations. It is also interesting to note that the impact of changing the rate coefficients of a number of reactions flips from promoting (shortening ignition time) to inhibitive (delaying ignition) for high-pressure conditions (10 atm to $34 \mathrm{~atm}$, compared to $2 \mathrm{~atm})$. This switching behavior is due to recombination reactions ( $\mathrm{NO}+\mathrm{O}+\mathrm{M} \leftrightarrows \mathrm{NO}_{2}+\mathrm{M}$ (R7), $\mathrm{H}+\mathrm{CO}+\mathrm{M} \leftrightarrows \mathrm{HCO}+\mathrm{M}(-\mathrm{R} 5))$ reducing radical pools at high pressures, and therefore also changing the net direction of the reaction $\mathrm{NO}_{2}+\mathrm{H} \leftrightarrows \mathrm{NO}+\mathrm{OH}(\mathrm{R} 8)$, which then removes $\mathrm{H}$-atoms at high pressures instead of producing $\mathrm{H}$-atoms at low pressures.

The sensitivity analysis performed with Chemkin Pro and the mechanism proposed in the present study for the top 10 most-sensitive reactions, on the lowest and highest temperatures investigated for each mixture and pressure conditions, led to a total of 38 different reactions. Many of these reactions have a moderate sensitivity coefficient and, as described above, are condition specific. However, a few reactions were found sensitive in most of the cases. A list of these most-sensitive and -common reactions is provided in Table 4, while the complete results of this sensitivity analysis are provided as supplemental material for all mixtures.

Table 4: List of the 10 most-common sensitive reactions obtained during this study. The order of the reactions corresponds to the order of appearance of the reaction in the model, not to the relative value of the sensitivity coefficient.

\begin{tabular}{|l|l|}
\hline \multicolumn{1}{|c|}{ Reaction } & Reaction number \\
\hline $\mathrm{CH}_{3} \mathrm{NO}_{2} \leftrightarrows \mathrm{CH}_{3}+\mathrm{NO}_{2}$ & R1 \\
\hline $\mathrm{CH}_{3}+\mathrm{NO}_{2} \leftrightarrows \mathrm{CH}_{3} \mathrm{O}+\mathrm{NO}$ & R2 \\
\hline $\mathrm{CH}_{3} \mathrm{NO}_{2} \leftrightarrows \mathrm{CH}_{3} \mathrm{O}+\mathrm{NO}$ & R3 \\
\hline $\mathrm{H}+\mathrm{O}_{2} \leftrightarrows \mathrm{O}+\mathrm{OH}$ & $\mathrm{R} 4$ \\
\hline $\mathrm{HCO}+\mathrm{M} \leftrightarrows \mathrm{H}+\mathrm{CO}+\mathrm{M}$ & $\mathrm{R} 5$ \\
\hline $\mathrm{HCO}+\mathrm{NO} \leftrightarrows \mathrm{HNO}+\mathrm{CO}$ & R6 \\
\hline $\mathrm{NO}_{2}+\mathrm{H} \leftrightarrows \mathrm{NO}+\mathrm{OH}$ & $\mathrm{R} 8$ \\
\hline $\mathrm{HCO}+\mathrm{O}_{2} \leftrightarrows \mathrm{CO}+\mathrm{HO}_{2}$ & R9 \\
\hline $\mathrm{CH}_{2} \mathrm{O}+\mathrm{OH} \leftrightarrows \mathrm{HCO}+\mathrm{H}_{2} \mathrm{O}$ & R10 \\
\hline $\mathrm{CH}_{3}+\mathrm{H}(+\mathrm{M}) \leftrightarrows \mathrm{CH}_{4}(+\mathrm{M})$ & R11 \\
\hline
\end{tabular}


To compare the important reactions for the ignition delay time of each mechanism, the sensitivity analysis was conducted for Mix 8 (stoichiometric condition, around 9 atm) at 1055 and $895 \mathrm{~K}$ (matching the extremes in temperatures investigated experimentally), which corresponds to the lowest level of dilution investigated (90\% Ar) and to a condition where large differences were observed amongst the models (see Fig. 9).

The sensitivity analysis was conducted on $\mathrm{OH}^{*}$ by determining the value of the normalized $\mathrm{OH}^{*}$ reaction sensitivities at the time of the second $\mathrm{OH}^{*}$ emission peak $(\sigma)$. The 10 reactions with the largest value of $\sigma$ were identified for each mechanism, for each experiment. Figure 18 presents the normalized sensitivity coefficient $(\sigma)$ for the reactions that were common to at least two mechanisms; the other reactions being typically of smaller importance, or are addressed if otherwise. As can be seen in Fig. 18 for the $895 \mathrm{~K}$ case, the three mechanisms share the same most-sensitive (promoting) reactions:

$$
\mathrm{CH}_{3} \mathrm{NO}_{2}(+\mathrm{M}) \leftrightarrows \mathrm{CH}_{3}+\mathrm{NO}_{2}(+\mathrm{M})(\mathrm{R} 1)
$$

(Note that this reaction is written $\mathrm{CH}_{3} \mathrm{NO}_{2} \leftrightarrows \mathrm{CH}_{3}+\mathrm{NO}_{2}$ in the mechanism of the present study, as in Annesley et al. [22]) As well as the same most-inhibitive reaction:

$$
\mathrm{CH}_{3} \mathrm{NO}_{2}+\mathrm{OH} \leftrightarrows \mathrm{CH}_{2} \mathrm{NO}_{2}+\mathrm{H}_{2} \mathrm{O}(\mathrm{R} 12)
$$

The two literature mechanisms use basically the same reaction coefficient for R1 (from Glarborg et al. [13], or a very close rate for Brequigny et al.) whereas the reaction coefficient from Annesley et al. is used for the present study. Note that, at this temperature, the reaction $\mathrm{R} 3\left(\mathrm{CH}_{3} \mathrm{NO}_{2} \leftrightarrows \mathrm{CH}_{3} \mathrm{O}+\mathrm{NO}\right)$ is among the 10 most-sensitive reactions for the mechanism of the present study, but with a moderate sensitivity coefficient $\sigma$ $=0.16$. However, this reaction is even less sensitive at higher temperature $(1055 \mathrm{~K}$, not among the 10 mostsensitive reactions). The reaction coefficient for R12 is also different between this study (reaction coefficient from Tricot et al. [50]) and the two other models (from Glarborg et al. [13], with slightly more than an order of magnitude difference between the two reaction rates), which explains the large difference in the normalized sensitivity coefficient between this study $(\sigma=-0.33)$ and the others $(\sigma=-0.59$ and -0.71 for Brequigny et al. and Zhang et al., respectively). Figure 18 indicates that at $895 \mathrm{~K}$ reactions other than R1 have a relatively small sensitivity coefficient for the current model, more so than the other models. For example, the promoting reaction R2 is the reaction with the second largest value of $\sigma$ for the model of this study and the model of Zhang and coworkers, but large differences are observed between their respective normalized sensitivity coefficients $(\sigma=0.36$ and 0.95 , respectively).

$$
\mathrm{CH}_{3}+\mathrm{NO}_{2} \leftrightarrows \mathrm{CH}_{3} \mathrm{O}+\mathrm{NO}(\mathrm{R} 2)
$$

This reaction also has a relatively large sensitivity coefficient in the model of Brequigny et al. $(\sigma=0.68)$ but is not as important as R10 $(\sigma=0.80)$, which is also an important reaction for the other models.

$$
\mathrm{CH}_{2} \mathrm{O}+\mathrm{OH} \leftrightarrows \mathrm{HCO}+\mathrm{H}_{2} \mathrm{O}(\mathrm{R} 10)
$$

Note that amongst the models tested herein, R2 and R10 have essentially the same reaction rates under the conditions of the present study. The only other reaction that is common to the 3 mechanisms is the 
reaction R13. Note that the sensitivity coefficient for R13 is rather small for all the models, and each model uses the same rate of reaction for R13.

$$
\mathrm{CH}_{2} \mathrm{NO}_{2} \leftrightarrows \mathrm{CH}_{2}+\mathrm{NO}_{2}(\mathrm{R} 13)
$$

Finally, it is worth mentioning that reaction $\mathrm{R} 9\left(\mathrm{H}+\mathrm{O}_{2} \leftrightarrows \mathrm{O}+\mathrm{OH}(\mathrm{R} 4)\right)$ is usually the most-sensitive reaction for the ignition of hydrocarbons at shock-tube conditions [51-52]. However, due to both the low temperatures reached with NM (895 K in the present low-temperature case in Fig. 18) and the importance of $\mathrm{R} 1$, the reaction R4 appears only in the top 10 most-sensitive reactions for the model of Brequigny et al. and the model of the present study, with a moderate sensitivity coefficient. Note that the reaction coefficient for R4 used in the model of the present study (taken from the recent work from Kéromnès et al. [53]) is around $55 \%$ slower than the reaction coefficient used in the other mechanisms at this low-temperature condition. For the high-temperature case, $1055 \mathrm{~K}, \mathrm{R} 4$ is the most-sensitive (promoting) reaction for the model of the present study and for the model of Brequigny and coworkers. This reaction is the second most important promoting reaction for the model of Zhang et al., the most-sensitive (and promoting) reaction being R1 (also a sensitive reaction for the other models, but with a moderate sensitivity coefficient, $\sigma=0.20$ and 0.25 for the models of this study and Brequigny et al., respectively).

At this temperature, $\mathrm{R} 9$ is also a very sensitive reaction that promotes the reactivity of the mixture, for all mechanisms. The reaction coefficient used for this reaction is around two times faster for the model of the present study (reaction coming from the mechanism of Kéromnès et al. [53]) than for the other models (both using the same rate, from Desain et al. [54])

$$
\mathrm{HCO}+\mathrm{O}_{2} \leftrightarrows \mathrm{CO}+\mathrm{HO}_{2}(\mathrm{R} 9)
$$

Among the other sensitive reactions at $1055 \mathrm{~K}$, one can mention that R6 strongly inhibits the reactivity in the model of Zhang et al. $(\sigma=-0.66)$ and more moderately in the model of Brequigny et al. $(\sigma=-0.17)$, whereas this reaction is not among the 10 most-sensitive reactions for the model of the present study. For the model of the present study and for the model of Brequigny et al., the most important inhibiting reaction is R3 ( $\sigma=-0.76$ and -0.78 , respectively, both models using the same rate from Xu et al. [46]), and this reaction is also important for the model of Zhang et al. ( $\sigma=-0.47$, using the rate from Dammeier et al. [55]). Note that R3 also has a noticeable importance for the model of the present study and the model of Brequigny et al. at $895 \mathrm{~K}$, whereas R6 was not in the 10 most-sensitive reactions for the model of Zhang and coworkers at low temperature.

$$
\mathrm{HCO}+\mathrm{NO} \leftrightarrows \mathrm{HNO}+\mathrm{CO}(\mathrm{R} 6)
$$

Other important reactions from this sensitivity analysis are R2 (promoting, $\sigma=0.30$ and 0.55 , respectively for the model of this study and from Brequigny et al.), R12 (literature models only) and R14 and R8 (inhibiting with a moderate sensitivity coefficient, this study and Brequigny et al. only, both models sharing the same reaction rates):

$$
\begin{gathered}
\mathrm{NO}_{2}+\mathrm{H} \leftrightarrows \mathrm{NO}+\mathrm{OH}(\mathrm{R} 8) \\
\mathrm{CH}_{3}+\mathrm{HNO} \leftrightarrows \mathrm{NO}+\mathrm{CH}_{4}(\mathrm{R} 14)
\end{gathered}
$$


From the results of the sensitivity analysis performed under the conditions presented in Fig. 18, it can be concluded that only a few reactions are important to control the ignition of nitromethane (note that, as seen before and in Table 4, a different conclusion could be found for other mixtures and conditions). For the case presented in Fig. 18, many of the sensitive reactions have the same or very similar reaction coefficients in all the models, so a large portion of the noticeable difference between the models must be due to the differences in the reaction coefficients for $\mathrm{R} 4, \mathrm{R} 9$, and $\mathrm{R} 12$.

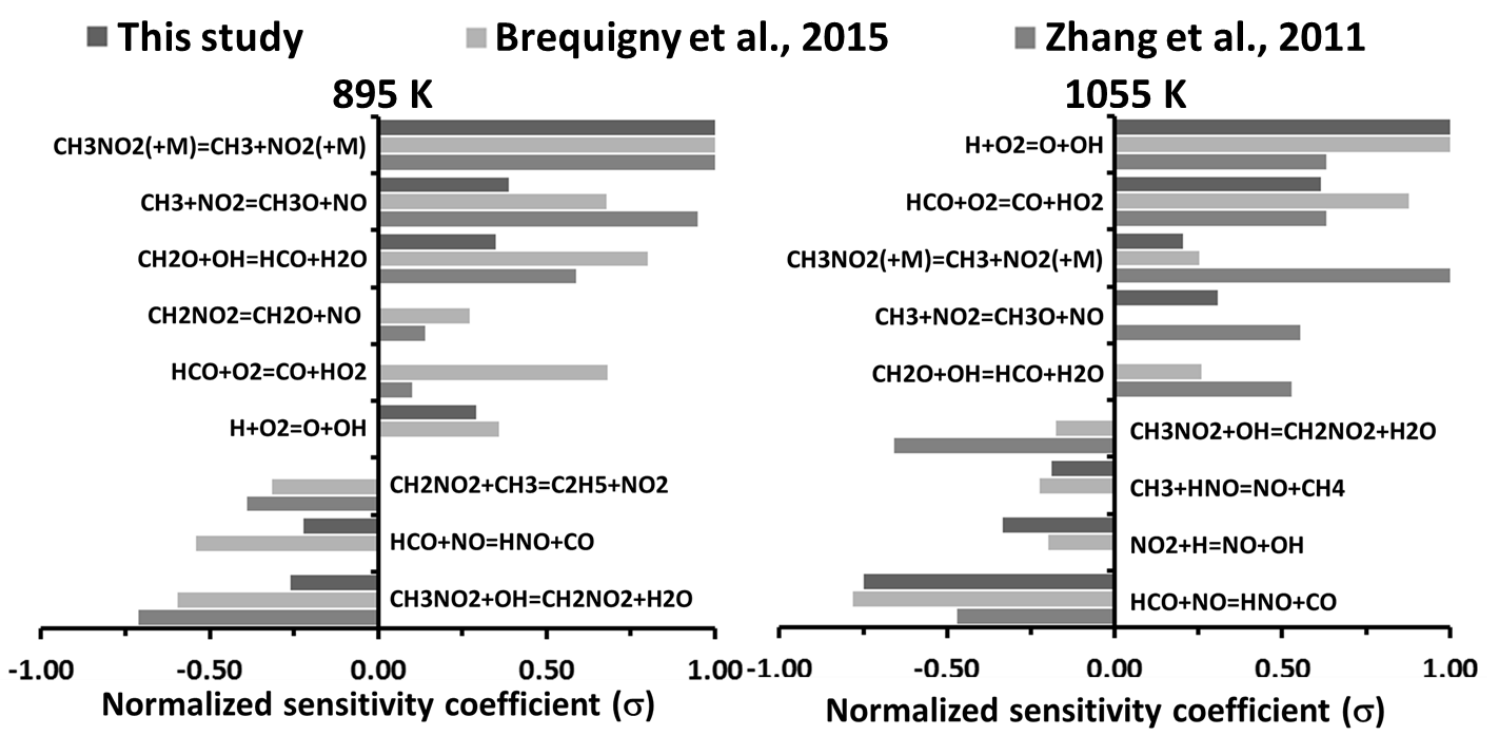

Figure 18: normalized sensitivity coefficient for the model of the present study and the models of Brequigny et al. [3] and Zhang et al. [14] for the two extreme temperatures of Mix 9 (895 and $1055 \mathrm{~K}$ ).

The reaction pathway analysis module from Chemkin Pro was used to exhibit the differences between the models when predicting NM profiles decomposition from Gläntzer and Troe [47]. Results for a reaction time of $40 \mu \mathrm{s}$, corresponding to the time at which around $50 \%$ of the NM is consumed in Fig. 11, are presented in Fig. 19. As can be seen in this figure, the reaction $\mathrm{R} 1\left(\mathrm{CH}_{3} \mathrm{NO}_{2}(+\mathrm{M}) \leftrightarrows \mathrm{CH}_{3}+\mathrm{NO}_{2}(+\mathrm{M})\right.$ or $\mathrm{CH}_{3} \mathrm{NO}_{2} \leftrightarrows \mathrm{CH}_{3}+\mathrm{NO}_{2}$ as written in Annesley et al. [22]) is by far the most important reaction for the NM decomposition under these conditions. It is worth noting that importance of R1 remains very large regardless of the reaction time and the temperature ( $\mathrm{R} 1$ is actually more important for NM decomposition as the temperature increases). One can notice in Fig. 19 that all the models have a similar molar flux for the NM decomposition through R1, between 87.6 and $92.0 \%$. The models are also in agreement with the small importance of R15 on the NM decomposition profile:

$$
\mathrm{CH}_{3} \mathrm{NO}_{2}+\mathrm{CH}_{3} \leftrightarrows \mathrm{CH}_{2} \mathrm{NO}_{2}+\mathrm{CH}_{4}(\mathrm{R} 15)
$$

Aside from these two common reactions, some noticeable differences can be observed between models. For example, the models from the present study and from Annesley et al. are the only models where the thermal decomposition of NM is not only due to R1 but also to R3, with a noticeable molar flux (7.1 and $6.5 \%$, respectively):

$$
\mathrm{CH}_{3} \mathrm{NO}_{2} \leftrightarrows \mathrm{CH}_{3} \mathrm{O}+\mathrm{NO}(\mathrm{R} 3)
$$


The second most important pathway for NM decomposition for the models of Zhang et al. and Brequigny et al. is the reaction between $\mathrm{NM}$ and the hydroxyl radical leading to water and $\mathrm{CH}_{2} \mathrm{NO}_{2}(\mathrm{R} 12)$. This pathway has a molar flux between 3.8 and $3.1 \%$ for the two aforementioned models, but it is interesting to mention that the molar flux is only $0.2 \%$ for the model of Annesley and coworkers and $2.3 \%$ for the model of the present study.

$$
\mathrm{CH}_{3} \mathrm{NO}_{2}+\mathrm{OH} \leftrightarrows \mathrm{CH}_{2} \mathrm{NO}_{2}+\mathrm{H}_{2} \mathrm{O}(\mathrm{R} 12)
$$

Nitromethane can also react with the radical $\mathrm{H}$ to either produce $\mathrm{H}_{2}$ and $\mathrm{CH}_{2} \mathrm{NO}_{2}(\mathrm{R} 16)$ or methyl and $\mathrm{HNO}_{2}$ (R17) (and, for the model of this study, HONO (R18)). As can be seen in Fig. 19, the molar flux for R16 is significantly smaller for the model of the present study $(<0.1 \%)$ than for the other mechanisms (between 1.3 and 2.3\%). The other pathway with a hydrogen radical that leads to the formation of a methyl radical and $\mathrm{HNO}_{2}(/ \mathrm{HONO})$ was not considered in the model of Annesley et al., whereas only the $\mathrm{HNO}_{2}$ reaction (R16) was considered in the model of Brequigny et al. and Zhang and coworkers.

$$
\begin{gathered}
\mathrm{CH}_{3} \mathrm{NO}_{2}+\mathrm{H} \leftrightarrows \mathrm{CH}_{2} \mathrm{NO}_{2}+\mathrm{H}_{2} \text { (R16) } \\
\mathrm{CH}_{3} \mathrm{NO}_{2}+\mathrm{H} \leftrightarrows \mathrm{CH}_{3}+\mathrm{HNO}_{2} \text { (R17) } \\
\mathrm{CH}_{3} \mathrm{NO}_{2}+\mathrm{H} \leftrightarrows \mathrm{CH}_{3}+\mathrm{HONO} \text { (R18) }
\end{gathered}
$$

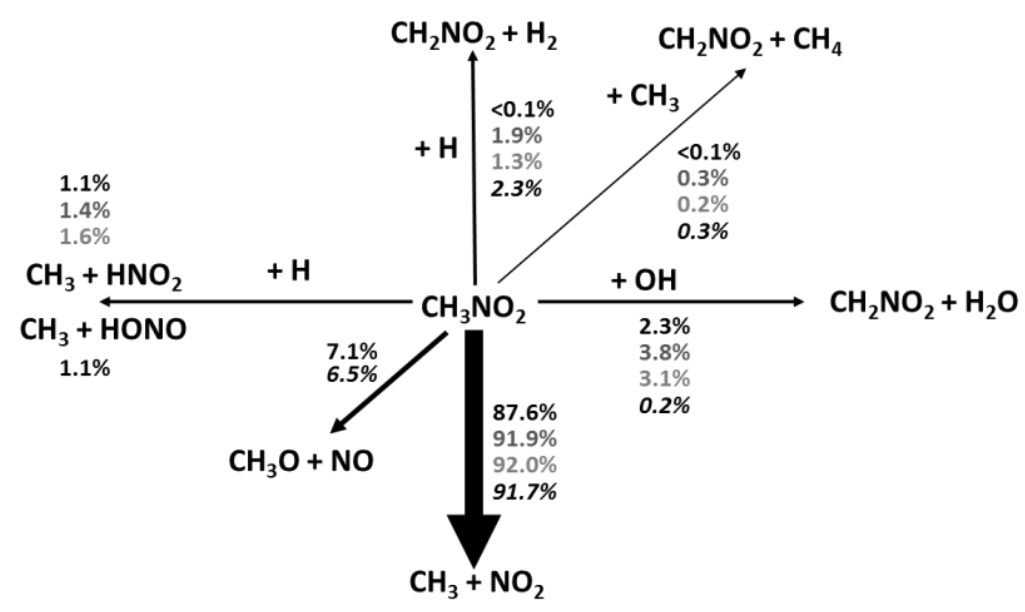

Figure 19: Reaction pathway analysis for nitromethane decomposition at $1180 \mathrm{~K}, 5.95 \mathrm{~atm}$ for a mixture of nitromethane diluted in $99.963 \%$ Ar. The black numbers correspond to the molar fluxes for the model of the present study; the grey ones for the model of Brequigny et al. [3]; the light grey values are for the model of Zhang et al. [14]; and the italic black ones are for the model of Annesley and coworkers [22].

This molar flux analysis exhibits the very large importance of R1 on the decomposition profile of NM. The reaction rate for R1 determined by Glarborg et al. [13] was used in the models of Zhang et al. and Brequigny and coworkers (although the later essentially used a very close value (Table 3)) while the new rate of Annesley et al. was used in the present study. This new rate in conjunction with $\mathrm{R} 3\left(\mathrm{CH}_{3} \mathrm{NO}_{2} \leftrightarrows \mathrm{CH}_{3} \mathrm{O}+\right.$ $\mathrm{NO})$ provides the same good level of predictions for NM decomposition as per Fig. 11. However, since NM decomposes thermally via R1 and R3 (Fig. 19) and not R1 only, the product composition is different and that should allow for better predictions on intermediate combustion species. More experiments are however 
required to fully validate this point. A reaction pathway analysis similar to Fig. 19 was carried out for the other conditions investigated during this study. Results show that, for all the conditions investigated, the NM consumption is largely dominated by its thermal dissociation via R1 and R3.

\section{6-Summary}

During this study, new ignition delay time measurements were performed over wide ranges of pressure, temperature, dilution level, and equivalence ratio conditions never investigated before. The results showed that the ignition delay time of nitromethane was sensitive to most of these parameters. The resulting experimental data were used to validate a detailed kinetics mechanism assembled from previous works from the authors and from recent literature work on nitromethane. The model proposed in the present study reproduces with good agreement the experimental data presented herein as well as most of the literature data, although there is still room for improvement.

The numerical chemical analysis showed that a relatively large amount of reactions are important for NM ignition. However, the relative importance of these reactions is strongly condition dependent. The sensitivity analysis performed for several models show that differences between the models are due to a relatively low number of reactions, from both the hydrocarbon and nitromethane/NOx sub-mechanisms. Among these reactions, the thermal decomposition of nitromethane ( $\mathrm{R} 1) \mathrm{CH}_{3} \mathrm{NO}_{2}(+\mathrm{M}) \leftrightarrows \mathrm{CH}_{3}+\mathrm{NO}_{2}(+\mathrm{M})$ ) is of primary importance. This reaction was recently updated through high-level calculations by Annesley et al. [22], and a roaming reaction was added to the chemical scheme ((R3) $\left.\mathrm{CH}_{3} \mathrm{NO}_{2} \leftrightarrows \mathrm{CH}_{3} \mathrm{O}+\mathrm{NO}\right)$. It can be concluded that the present study improves the overall predictions of nitromethane ignition. However, more data are still needed to further validate the nitromethane sub-mechanism and improve the predictions. The computed $\mathrm{OH}^{*}$ profiles also exhibit the need to improve on the $\mathrm{CH}$ radical chemistry predictions.

\section{7-Acknowledgments}

The TAMU part of this material is based partly upon the work supported by UTSR grant from the Department of Energy, NETL, under Award Number DE-FE0011778 and partly by the TEES Turbomachinery Laboratory. The authors would like to thank Dr. Robert Tranter and Dr. Stephen Klippenstein from Argonne National Laboratory for providing the calculated reaction rates for nitromethane decomposition in Ar. Claire Gregoire, visiting scholar from Université d'Orléans, France is acknowledged for her help in performing some of the experiments.

\section{8- References}

[1] Cracknell RF, Andrae JCG, McAllister LJ, Norton M, Walmsley HL. The chemical origin of octane sensitivity in gasoline fuels containing nitroalkanes. Combust. Flame 156 (2009) 1046-1052.

[2] Kalghatgi GT. Auto-ignition Quality of Practical Fuels and Implication for Fuel Requirements of Future SI and HCCI Engines. SAE Technical Paper 2005-01-0329.

[3] Brequigny P, Dayma G, Halter F, Mounaïm-Rousselle C, Dubois T, Dagaut P. Laminar burning velocities of premixed nitromethane/air flames: An experimental and kinetic modeling study. Proceed. Combust. Instit. 35, 2015, 7003-710.

[4] Guirguis R, Hsu D, Bogan D, Oran E. A mechanism for ignition of high-temperature gaseous nitromethane-The key role of the nitro group in chemical explosives. Combust. Flame 61 (1985) 51-62.

[5] Boyer E., Kuo K. Modeling of nitromethane flame structure and burning behavior. Proceed. Combust. Instit. 31 (2007) 2045-2053.

[6] McCown III KW, Petersen EL. Effects of nano-scale additives on the linear burning rate of nitromethane. Combust. Flame 161 (2014) 1935-1943.

[7] Menikoff R, Shaw MS. Modeling detonation waves in nitromethane. Combust.Flame 158 (2011) 2549-2558. 
[8] Bouyer V, Darbord I, Hervé P, Baudin G, Le Gallic C, Clément F, Chavent G. Shock-to-detonation transition of nitromethane: Time-resolved emission spectroscopy measurements. Combust. Flame 144 (2006) 139-150.

[9] Leal-Crouzet B, Baudin G, Presles HN. Shock initiation of detonation in nitromethane. Combust.Flame 122 (2000) 463-473.

[10] Gois JC, Presles HN, Vidal P. Effect of hollow heterogeneities on nitromethane detonation. Progr. Astronautics Aeronautics 153 (1993) 462-470.

[11] Prestes HN, Vidal P, Gois JC, Khasainov BA, Ermolaev BS. Influence of glass microballoons size on the detonation of nitromethane based mixtures. Shock Waves 4 (1995) 325-329.

[12] Hardesty DR. An investigation of the shock initiation of liquid nitromethane. Combust. Flame 27 (1976) 229-251.

[13] Glarborg P, Bendtsen AB, Miller JA. Nitromethane Dissociation: Implications For the $\mathrm{CH}_{3}+\mathrm{NO}_{2}$ Reaction. Int. J. Chem. Kinet. 31 (1999) 591-602.

[14] Tian Z, Zhang L, Li Y, Yuan T, Qi F. An experimental and kinetic modeling study of a premixed nitromethane flame at low pressure. Proceed. Combust. Instit. 32 (2009) 311-318.

[15] Zhang Z, Li Y, Yuan T, Cai J, Glarborg P, Qi F. An experimental and kinetic modeling study of premixed nitromethane flames at low pressure. Proceed. Combust. Instit. 33 (2011) 407-414.

[16] Nauclér JD, Nilsson EJK, Konnov AA. Laminar burning velocity of nitromethane + air flames: A comparison of flat and spherical flames. Combust. Flame 162 (2015) 3803-3809.

[17] Mathieu O, Goulier J, Gourmel F, Mannan MS, Chaumeix N, Petersen EL. Experimental study of the effect of $\mathrm{CF}_{3} \mathrm{I}$ addition on the ignition delay time and laminar flame speed of methane, ethylene, and propane. Proceed. Combust. Instit. 35 (2015) 2731-2739.

[18] Comandini A, Dubois T, Chaumeix N. Laminar flame speeds of n-decane, n-butylbenzene, and npropylcyclohexane mixtures. Proceed. Combust. Instit. 35 (2015) 671-678.

[19] Kang JG, Lee SW, Yun SS, Choi SN, Kim CS. Ignition delay times of nitromethane-oxygen-argon mixtures behind reflected shock. Combust. Flame 85 (1991) 275-278.

[20] Zhu R, Raghunath P, Lin MC. Effect of Roaming Transition States upon Product Branching in the Thermal Decomposition of $\mathrm{CH}_{3} \mathrm{NO}_{2}$. J. Phys. Chem. A 117 (2013) 7308-7313.

[21] Isegawa M, Lie F, Maeda S, Morokuma K. Ab Initio Reaction Pathways for Photodissociation and Isomerization of Nitromethane on Four Singlet Potential Energy Surfaces with Three Roaming Paths. J. Chem. Phys. 140 (2014) 244310. [22] Annesley CJ, Randazzo JB, Klippenstein SJ, Harding LB, Jasper AW, Georgievskii Y, Ruscic B, Tranter RS.

Thermal Dissociation and Roaming Isomerization of Nitromethane: Experiment and Theory. J. Phys. Chem. A 119 (2015) 7872-7893.

[23] Wodtke AM, Hintsa EJ, Lee YT. Infrared multiphoton dissociation of three nitroalkanes. J. Phys. Chem. 90 (1986) 3549-3558.

[24] Aul CJ, Metcalfe WK, Burke SM, Curran HJ, Petersen EL. Ignition and kinetic modeling of methane and ethane fuel blends with oxygen: A design of experiments approach. Combust. Flame 160 (2013) 1153 - 1167.

[25] Petersen EL, Rickard MJA, Crofton MW, Abbey ED, Traum MJ, Kalitan DM. A facility for gas-and condensedphase measurements behind shock waves. Meas. Sci. Technol. 16 (2005) 1716-1729.

[26] Mathieu O, Petersen EL. Experimental and modeling study on the high-temperature oxidation of Ammonia and related NOx chemistry. Combust. Flame 162 (2015) 554-570.

[27] Mathieu O, Pemelton JM, Bourque G, Petersen EL. Shock-induced ignition of methane sensitized by $\mathrm{NO}_{2}$ and $\mathrm{N}_{2} \mathrm{O}$. Combustion and Flame 162 (2015) 3053-3070.

[28] Hall JM, Petersen EL. An optimized kinetics model for OH chemiluminescence at high temperatures and atmospheric pressures. Int. J. Chem. Kinet. 38 (2006) 714-724.

[29] Hidaka Y, Takuma H, Suga M. Shock-tube study of the rate constant for excited hydroxyl (OH*(2.SIGMA.+)) formation in the nitrous oxide-molecular hydrogen reaction. J. Phys. Chem. 89 (1985) 4903-4905.

[30] Ross PJ. Taguchi Techniques for Quality Engineering, McGraw-Hill, 1996.

[31] Rotavera B, Petersen EL. Blending effects on ignition delay times of methyl octanoate/n-

nonane/methylcyclohexane. Fuel 115 (2014) 264 - 281.

[32] Donohoe N, Heufer A, Metcalfe WK, Curran HJ, Davis ML, Mathieu O, Plichta D, Morones A, Petersen EL, Güthe F. Ignition delay times, laminar flame speeds, and mechanism validation for natural gas/hydrogen blends at elevated pressures Combust. Flame 161 (2014) 1432 - 1443.

[33] Rotavera B, Dagaut P, Petersen EL. Chemical kinetics modeling of n-nonane oxidation in oxygen/argon using excited-state species time histories. Combust. Flame 161 (2014) 1146 - 1163.

[34] Kalitan DM, Hall JM, Petersen EL. Ignition and Oxidation of Ethylene-Oxygen-Diluent Mixtures with and Without Silane. Journal of Propulsion and Power 21 (2005) 1045-1056. 
[35] de Vries J, Hall JM, Simmons SL, Rickard MJA, Kalitan DM, Petersen EL. Ethane ignition and oxidation behind reflected shock waves. Combust. Flame 150 (2007) 137-150.

[36] Petersen EL, Davidson DF, Hanson RK. Kinetics Modeling of Shock-Induced Ignition in Low Dilution $\mathrm{CH}_{4} / \mathrm{O}_{2}$ Mixtures at High Pressures and Intermediate Temperatures. Combust. Flame 117 (1999) 272-290.

[37] Mathieu O, Levacque A, Petersen EL. Effects of $\mathrm{N}_{2} \mathrm{O}$ addition on the ignition of $\mathrm{H}_{2}-\mathrm{O}_{2}$ mixtures: Experimental and detailed kinetic modeling study. Int. J. Hydrogen Energy 37 (2012) 15393-15405.

[38] Mathieu O, Levacque A, Petersen EL. Effects of $\mathrm{NO}_{2}$ addition on hydrogen ignition behind reflected shock waves. Proceed. Combust. Instit. 34 (2013) 633-640.

[39] Metcalfe WK, Burke SM, Ahmed SS, Curran HJ. A Hierarchical and Comparative Kinetic Modeling Study of C1 C2 Hydrocarbon and Oxygenated Fuels. Int. J. Chem. Kinet. 45 (2013) 638-675.

[40] Mével R, Javoy S, Lafosse F, Chaumeix N, Dupré G, Paillard CE. Hydrogen-nitrous oxide delay times: Shock tube experimental study and kinetic modelling. Proceed. Combust. Instit. 32 (2009) 359-366.

[41] Dayma G, Dagaut P. Effects of air contamination on the combustion of hydrogen —effect of $\mathrm{NO}$ and $\mathrm{NO}_{2}$ addition on hydrogen ignition and oxidation kinetics. Combust. Sci. Technol. 178 (2006) 1999-2024.

[42] Sivaramakrishnan R, Brezinsky K, Dayma G, Dagaut P. High pressure effects on the mutual sensitization of the oxidation of $\mathrm{NO}$ and $\mathrm{CH}_{4}-\mathrm{C}_{2} \mathrm{H}_{6}$ blends. Phys. Chem. Chem. Phys. 9 (2007) 4230-4244.

[43] Dagaut P, Glarborg P, Alzueta MU. The oxidation of hydrogen cyanide and related chemistry. Prog. Energy Combust. Sci. 34 (2008) 1-46.

[44] CHEMKIN-PRO 15131, Reaction Design, San Diego, 2013.

[45] D. G. Goodwin, H. K. Moffat, R. L. Speth. Cantera: An object- oriented software toolkit for chemical kinetics, thermodynamics, and transport processes. http:// www.cantera.org, 2016. Version 2.2.1.

[46] Xu ZF, Hsu CH, Lin MC. Ab initio kinetics of the reaction of HCO with NO: Abstraction versus association/elimination mechanism. J. Chem. Phys. 122 (2005) 234308.

[47] Glänzer K, Troe J. Thermische Zerfallsreaktionen von Nitroverbindungen I: Dissoziation von Nitromethan. Helv. Chim Acta. 55 (1972) 2884-2893.

[48] Hsu DSY, Lin MC. Laser probing and kinetic modeling of NO and CO production in shock-wave decomposition of nitromethane under highly diluted conditions. J. Energetic Mater 3 (1985) 95-127.

[49] Zhang YX, Bauer SH. Modeling the Decomposition of Nitromethane, Induced by Shock Heating. J Phys Chem 101 (1997) 8717-8726.

[50] Tricot JC, Perche A, Lucquin M. Gas phase oxidation of nitromethane. Combust. Flame 40 (1981) 269-291.

[51] Burke S., Burke U., Mathieu O, Osorio I, Keesee C, Morones A, Petersen EL, Wang W, DeVerter T, M.

Oehlschlaeger M, Rhodes B, Hanson H, Davidson D, Weber B, Sung CJ, Santner J, Ju Y, Haas F, Dryer F, Volkov E,

Nilsson E, Konnov A, Alrefae M, Khaled F, Farooq A, Dirrenberger P, Glaude PA, Battin-Leclerc F, H. Curran HJ. An experimental and modeling study of propene oxidation. Part 2: Ignition delay time and flame speed measurements.

Combust. Flame 162 (2015) 296-314.

[52] Westbrook CK, Pitz WJ, Mehl, Glaude PA, Herbinet O, Bax S, Battin-Leclerc F, Mathieu O, Petersen EL, Bugler J, Curran HJ. An Experimental and Kinetic Modeling Study of 2-Methyl-2-Butene: Allylic Hydrocarbon Kinetics. J. Phys. Chem. A 119 (2015) 7462-7480.

[53] Kéromnès A, Metcalfe WK, Heufer KA, Donohoe N, Das AK, Sung CJ, Herzler J, Naumann C, Griebel P, Mathieu O, Krejci MC, Petersen EL, Pitz WJ, Curran HJ. An experimental and detailed chemical kinetic modeling study of hydrogen and syngas mixture oxidation at elevated pressures. Combust. Flame 160 (2013) 995-1011.

[54] DeSain JD, Jusinski LE, Ho AD, Taatjes CA. Temperature dependence and deuterium kinetic isotope effects in the HCO(DCO)+O-2 reaction between 296 and 673 K. Chemical Physics Letters 347 (2001) 79-86.

[55] Dammeier J, Colberg M, Friedrichs G. Wide temperature range ( $T=295 \mathrm{~K}$ and $770-1305 \mathrm{~K}$ ) study of the kinetics of the reactions $\mathrm{HCO}+\mathrm{NO}$ and $\mathrm{HCO}+\mathrm{NO}_{2}$ using frequency modulation spectroscopy. Phys. Chem. Chem. Phys. 9 (2007) 4177-4188. 